\title{
A Suíte Intrusiva Rio Dourado - Um Granito Tipo A de 1,88 Ga - Sudeste do Craton Amazônico - Mato Grosso - Brasil
}

\author{
The Rio Dourado Intrusive Suite - 1.88 Ga A-type Granite - \\ Southeastern Amazonian Craton - Mato Grosso - Brazil
}

\author{
Márcia Aparecida de Sant'Ana Barros' (mapabarros@yahoo.com), \\ Márcio Martins Pimentel² (marcio.pimentel@ufrgs.br), Mara Luiza Barros Pita Rocha' (marapita1@yahoo.com.br), \\ Fernanda Rodrigues da Silva ${ }^{3}$ (fernandelas@gmail.com), Rosilene Aparecida Padilha' (rosilene_gel@yahoo.com.br), \\ Elton Luiz Dantas ${ }^{4}$ (elton@unb.br), Evelin de Moura' (eve.lin.moura@hotmail.com) \\ 'Departamento de Recursos Minerais - Instituto de Ciências Exatas e da Terra - UFMT \\ Av. Fernando Correa da Costa s/n, CEP 78060-900, Cuiabá, MT, BR \\ ${ }^{2}$ Instituto de Geociências - UFRGS, Porto Alegre, RS, BR \\ ${ }^{3}$ Instituto de Geociências - UNICAMP, Campinas, SP, BR \\ ${ }^{4}$ Departamento de Geologia Geral e Aplicada - Instituto de Geociências - UnB, Brasília, DF, BR
}

Recebido em 03 de novembro de 2010; aceito em 06 de janeiro de 2011

\section{RESUMO}

A Suíte Intrusiva Rio Dourado (SIRD) está constituída por rochas graníticas expostas na porção sudeste do Craton Amazônico, Província Amazônia Central, como corpos intrusivos na Suíte Intrusiva Vila Rica, de idade paleoproterozoica. Rochas vulcânicas félsicas de natureza dominantemente piroclástica (Grupo Iriri) são cogenéticas e ocorrem associadas espacialmente aos corpos intrusivos. Estudos petrográficos permitiram dividir os granitos da SIRD em: biotita granito, biotita granitos com anfibólio e granitos granofíricos. Análises de composição modal indicam composições variáveis entre sieno e monzogranitos. Valor médio da razão $\mathrm{FeO}_{\mathrm{T}} / \mathrm{Feo}_{\mathrm{T}}+\mathrm{MgO}$ em torno de 0,8 a 0,95, os altos teores de $\mathrm{FeO}_{\mathrm{T}}$ e baixos de $\mathrm{CaO}$, bem como o caráter fracamente peraluminoso, são comuns em granitos tipo A oxidados. Em diagramas de discriminação de ambiente tectônico, tais rochas ocupam o campo determinado para granitos pós-colisionais. Padrões de elementos terras raras mostram enriquecimento em ETRL com relação aos ETRP e anomalia negativa de Eu. Anomalias negativas de Ta e $\mathrm{Nb}$ e empobrecimento de elementos terras raras pesados, podem ser observadas em diagramas multielementar, feições comuns nos granitos tipo A de ambientes pós colisionais. Teores de $\mathrm{Ce}, \mathrm{Yb}, \mathrm{Nb}$ e Ga são transicionais entre os granitos tipo A1 e A2. Idade U-Pb por TIMS em zircão, para uma amostra de granito da SIRD, apresenta valor $1876 \pm 39$ Ma, enquanto valores de $\varepsilon_{\mathrm{Nd}}(\mathrm{T})$ negativos (-3 a -10) e idades modelo $\left(\mathrm{T}_{\mathrm{DM}}\right)$ entre 2,6 a 2,8 Ga sugerem origem a partir de refusão de crosta mais antiga, possivelmente arqueana.

Palavras-chave: Paleoproterozoico; Granito tipo A; Província Amazônia Central; Craton Amazônico.

\section{ABSTRACT}

The Rio Dourado Intrusive Suite (RDIS) is composed of granitic rocks which are exposed in the southeastern Amazon Craton, Central Amazon Province. These granites intruded into the Paleoproterozoic granites of the Vila Rica Intrusive Suite. The predominantly pyroclastic felsic volcanic rocks of the Iriri Group are coeval and spatially associated with the intrusive granites. Petrographic studies allow us to divide the Rio Dourado granites into: biotite granites, amphibole-bearing biotite granites and granophyric granites. Modal compositions range from monzo to syenogranites. The oxidized A-type granite is characterized by $\mathrm{FeO} / \mathrm{FeO}+\mathrm{MgO}$ ranging from $0.8-0.95$, high contents of $\mathrm{FeO}_{\mathrm{T}}$ and low contents of $\mathrm{CaO}$, as well as peraluminous composition. In the tectonic discrimination diagrams, samples of these granites plot in the post-collisional field. REE patterns show enrichment in the LREE relative to HREE and negative Eu anomalies. Negative anomalies of $\mathrm{Ta}$ and $\mathrm{Nb}$, as well as depletion in the HREE, features which are typical of A-type granites of post-collisional settings, are 
observed in multi-element diagrams,. $\mathrm{Ce}, \mathrm{Yb}, \mathrm{Nb}$ and $\mathrm{Ga}$ contents are transitional between those of $\mathrm{A} 2$ and $\mathrm{A} 1$-type granites. U-Pb zircon dating by TIMS yielded an age of $1876 \pm 39$, whereas negative values of $\varepsilon_{\mathrm{Nd}}(-3$ to -10$)$ and model ages $\left(\mathrm{T}_{\mathrm{DM}}\right)$ between 2.6 and $2.8 \mathrm{Ga}$ indicate it was formed by re-melting of older (possibly Archean) crust.

Keywords: Paleoproterozoic; A-type granite; Central Amazon Province; Amazonian Craton.

\section{INTRODUÇÃO}

A classe de granitos tipo A foi proposta pela primeira vez por Loiselle e Wones (1979), para descrever as rochas graníticas com teores elevados de $\mathrm{Na}_{2} \mathrm{O}+\mathrm{K}_{2} \mathrm{O}$, altos teores de $\mathrm{Zr}, \mathrm{Nb}$, Ta, elementos terras raras, alta razão $\mathrm{Fe}(\mathrm{Fe}+\mathrm{Mg})$ e baixas abundâncias de $\mathrm{Mg}, \mathrm{Fe}, \mathrm{Cr}, \mathrm{V}, \mathrm{Ni}$, $\mathrm{Cu}, \mathrm{Sc}, \mathrm{Ba}, \mathrm{Sr}$ e Eu, bem como baixo conteúdo de $\mathrm{H}_{2} \mathrm{O}$ e de fugacidade de oxigênio, diferindo, portanto, de rochas cálcio-alcalinas típicas (tipo I). Loiselle e Wones (1979) consideram que os granitos tipo A podem ser rochas peralcalinas, metaluminosas e fracamente peraluminosas, originadas em ambientes anorogênicos, zonas de rift ou blocos continentais estáveis.

Whalen, Curie e Chappell (1987) adicionaram como características típicas de granitos do tipo A, altos conteúdos de $\mathrm{SiO}_{2}, \mathrm{Ga}, \mathrm{Y}, \mathrm{Ce}$ e $\mathrm{Zn}$, alta razão de $\mathrm{Ga} / \mathrm{Al}$ e baixos conteúdos de $\mathrm{Al}_{2} \mathrm{O}_{3}$ e $\mathrm{CaO}$. Sugerem ainda que granitos tipo A podem variar desde altamente alcalinos até subalcalinos apresentando razões isotópicas $\mathrm{Rb}-\mathrm{Sr}$ e $\mathrm{Sm}-\mathrm{Nd}$ variáveis refletindo provavelmente a heterogeneidade de fonte.

Granitos Rapakivi foram redefinidos por Haapala e Rämö (1992) como granitos tipo A caracterizados pela textura rapakivi. $\mathrm{O}$ estudo destes granitos é muito importante para o entendimento da evolução magmática e tectônica de áreas pré-cambrianas (Dall'Agnol, Pichavant, Champenois, 1997). Séries graníticas rapakivi ocorrem no Craton Amazônico e mostram idades que variam de 1,88 a $0,9 \mathrm{Ga}$, representando, portanto, uma importante ferramenta de investigação da evolução da crosta continental nesta vasta área cratônica. Dall'Agnol et al. (1999a, 1999b), Bettencourt et al. (1999) e Pierosan (2009) sumarizaram o magmatismo no Craton Amazônico. Os dados são reapresentados neste trabalho na Tabela I e foram atualizados.

Este trabalho apresenta os resultados petrográficos, geoquímicos e isotópicos de uma importante suíte de granitos do tipo A, oxidados (a Suíte Intrusiva Rio Dourado SIRD), situada na porção sul da Província Amazônia Central, do Craton Amazônico, no nordeste de Mato Grosso. Os dados referem-se a uma porção do Craton Amazônico desconhecida da maioria da comunidade científica e dessa forma os resultados ora discutidos representam uma importante contribuição ao conhecimento sobre a evolução crustal do Craton Amazônico.

\section{MATERIAIS E MÉTODOS}

O Mapa geológico utilizado para a coleta de dados foi o mapa do estado de Mato Grosso, escala 1:1.000.000 do Serviço Geológico do Brasil, CPRM, (Lacerda Filho et al., 2004) e trabalhos de mapeamento de alunos de graduação da Universidade Federal do Mato Grosso (UFMT) (1:100.000) em algumas porções onde ocorre a SIRD.

Para a coleta das amostras, foram feitos perfis perpendiculares à estrutura principal dos corpos. Cerca de quarenta amostras foram coletadas em diferentes etapas de campo. Dez amostras foram cortadas em tabletes e submetidas à colorimetria (Cobalto-Nitrito de Sódio) para a estimativa de composição modal. As seções delgadas foram confeccionadas na UFMT. Das onze amostras de granitos da SIRD, seis (Fera 35, Fera 37 e Fera 17, 905, V4 e V1) são amostras já publicadas em outros trabalhos (Padilha, 2007; Padilha e Barros, 2008) que foram re-interpretadas em conjunto com as novas amostras analisadas neste trabalho. As amostras Z-25, Z-36, R-14, R-24, R-27B foram analisadas no Acmelabs - Canadá. $\mathrm{SiO}_{2}, \mathrm{Al}_{2} \mathrm{O}_{3}, \mathrm{TiO}_{2}, \mathrm{Fe}_{2} \mathrm{O}_{3}$, $\mathrm{CaO}, \mathrm{P}_{2} \mathrm{O}_{5}, \mathrm{MnO}$ e $\mathrm{MgO}$ foram dosados por fluorescência de Raios-X, $\mathrm{Na}_{2} \mathrm{O}$ e $\mathrm{K}_{2} \mathrm{O}$ por absorção atômica e $\mathrm{Pb}, \mathrm{Cu}, \mathrm{Li}$, Mo, K, F, B, Ni, Ba, Rb, Sr, Th, U, Zr, Nb, V, Y, Sc, Ga, Ta e Hf foram analisados por ICP-MS (Indutive Coupled Plasma-Mass Spectometre), assim como os elementos terras raras (La, Ce, $\mathrm{Nd}, \mathrm{Sm}, \mathrm{Eu}, \mathrm{Gd}, \mathrm{Dy}, \mathrm{Ho}, \mathrm{Er}, \mathrm{Yb}$ e Lu). Análises U-Pb em zircão e $\mathrm{Sm}-\mathrm{Nd}$ em rocha total foram realizadas no laboratório de geocronologia da UnB. Para $\mathrm{U}-\mathrm{Pb}$ em zircão duas amostras foram utilizadas a UFMT18 a Pt-251. Cada amostra de granito pesando $5 \mathrm{~kg}$ foi moída e bateada. A fração concentrada na bateia foi submetida à separação magnética usando imã de mão e separador Franz. Os zircões foram catados manualmente usando lupa binocular. Os zircões mais claros foram pesados, misturados com uma solução traçadora de $\mathrm{U}^{235}-\mathrm{Pb}^{205}$ e diluídos segundo o método de Parrish (1987). A extração de $\mathrm{Pb}$ e U foi realizada em microcolunas, seguindo técnicas convencionais descritas por Krogh (1973). A solução obtida foi secada com ácido fosfórico e carregada com sílica gel, usando filamento de Re. As composições isotópicas foram medidas num equipamento termo-iônico Finnigan-MAT 262 dotado de sete coletores tipo Faraday móveis e multiplicadora de elétrons central marca TIMS FINNIGAN MAT 262. 
Tabela 1. Dados geocronológicos dos principais granitos rapakivi da América do Sul, modificado de Dall'Agnol et al. (1999a, 1999b), Bettencourt et al. (1999) e Pierosan (2009). Abreviações: $\mathbf{Z r}=$ zircão; $\mathbf{R T}=$ rocha total; $\mathbf{1}=$ evaporação; 2 = SHRIMP; 3 = TIMS.

\begin{tabular}{|c|c|c|c|c|c|}
\hline \multicolumn{6}{|l|}{ Suíte Intrusiva Mapuera } \\
\hline Granito Madeira & sienogranito & $1829 \pm 2$ & ${ }^{1} \mathrm{~Pb}-\mathrm{Pb}$ & $\mathrm{zr}$ & Costi, Dall'Agnol e Moura (2000) \\
\hline Granito Simão & biotita sienogranito & $1875 \pm 4$ & ${ }^{1} \mathrm{~Pb}-\mathrm{Pb}$ & $\mathrm{zr}$ & Ferron et al. (2006) \\
\hline Granito Alalaú & - & $1876 \pm 4$ & ${ }^{2} \mathrm{U}-\mathrm{Pb}$ & $\mathrm{zr}$ & Santos et al. (2002) \\
\hline Granito Alalaú & - & $1879 \pm 3$ & ${ }^{2} \mathrm{U}-\mathrm{Pb}$ & $\mathrm{zr}$ & Santos et al. (2002) \\
\hline Granito Alalaú & - & $1880 \pm 3$ & ${ }^{2} \mathrm{U}-\mathrm{Pb}$ & $\mathrm{zr}$ & Santos et al. (2002) \\
\hline Granito Simão & biotita granito & $1882 \pm 4$ & ${ }^{1} \mathrm{~Pb}-\mathrm{Pb}$ & $\mathrm{zr}$ & Ferron et al. (2006) \\
\hline Granito Rastro & biotita felds. alc. Granito & $1882 \pm 2$ & ${ }^{1} \mathrm{~Pb}-\mathrm{Pb}$ & $\mathrm{zr}$ & Ferron et al. (2006) \\
\hline Granito Bom Futuro & sienogranito & $1882 \pm 3$ & ${ }^{1} \mathrm{~Pb}-\mathrm{Pb}$ & $\mathrm{zr}$ & Ferron et al. (2006) \\
\hline Granito Alto Pitinga & biotita monzogranito & $1885 \pm 3$ & ${ }^{1} \mathrm{~Pb}-\mathrm{Pb}$ & $\mathrm{zr}$ & Ferron et al. (2006) \\
\hline Granito Simão & biotita felds. alc. granito & $1885 \pm 4$ & ${ }^{1} \mathrm{~Pb}-\mathrm{Pb}$ & $\mathrm{zr}$ & Ferron et al. (2006) \\
\hline Granito Alto Pitinga & biotita monzogranito & $1888 \pm 3$ & ${ }^{1} \mathrm{~Pb}-\mathrm{Pb}$ & $\mathrm{zr}$ & Ferron et al. (2006) \\
\hline Batólito São Gabriel & biotita sienogranito & $1889 \pm 2$ & ${ }^{1} \mathrm{~Pb}-\mathrm{Pb}$ & $\mathrm{zr}$ & Valério, Souza e Macambira (2006) \\
\hline \multicolumn{6}{|l|}{ Suíte Intrusiva Maloquinha } \\
\hline Granito Maloquinha & biotita leucogranito & $1880 \pm 9$ & ${ }^{1} \mathrm{~Pb}-\mathrm{Pb}$ & $\mathrm{zr}$ & Lamarão et al. (2002) \\
\hline Granito Maloquinha & biotita-anfibólio granito & $1882 \pm 4$ & ${ }^{1} \mathrm{~Pb}-\mathrm{Pb}$ & $\mathrm{zr}$ & Vasquez e Klein (2000) \\
\hline \multicolumn{6}{|l|}{ Suíte Serra dos Carajás } \\
\hline Granito Pojuca & - & $1874 \pm 2$ & ${ }^{2} \mathrm{U}-\mathrm{Pb}$ & rt & Machado, Lindernmayer e Krogh (1991) \\
\hline Granito Serra dos Carajás & - & $1880 \pm 2$ & ${ }^{2} \mathrm{U}-\mathrm{Pb}$ & $\mathrm{rt}$ & Machado, Lindernmayer e Krogh (1991) \\
\hline Granito Cigano & - & $1883 \pm 2$ & ${ }^{2} \mathrm{U}-\mathrm{Pb}$ & $\mathrm{rt}$ & Machado, Lindernmayer e Krogh (1991) \\
\hline \multicolumn{6}{|l|}{ Suíte Jamon } \\
\hline Granito Redenção & - & $1870 \pm 68$ & ${ }^{1} \mathrm{~Pb}-\mathrm{Pb}$ & rt & Barbosa et al. (1995) \\
\hline Granito Musa & - & $1883+5 /-2$ & ${ }^{2} \mathrm{U}-\mathrm{Pb}$ & $\mathrm{rt}$ & Machado, Lindernmayer e Krogh (1991) \\
\hline Granito Jamon & Monzogranito & $1885 \pm 32$ & ${ }^{1} \mathrm{~Pb}-\mathrm{Pb}$ & $\mathrm{zr}$ & Dall'Agnol et al. (1999a) \\
\hline Granito Seringa & feldspato alcalino granito & $1893 \pm 30$ & ${ }^{1} \mathrm{~Pb}-\mathrm{Pb}$ & $\mathrm{zr}$ & Avelar et al. (1994) \\
\hline Diques félsicos & - & $1885 \pm 2$ & ${ }^{1} \mathrm{~Pb}-\mathrm{Pb}$ & $\mathrm{zr}$ & Oliveira (2001) \\
\hline \multicolumn{6}{|l|}{ Suíte Velho Guilherme } \\
\hline Granito Mocambo & - & $1862 \pm 32$ & ${ }^{1} \mathrm{~Pb}-\mathrm{Pb}$ & $\mathrm{zr}$ & Teixeira et al. (2002) \\
\hline Granito Rio Xingu & - & $1866 \pm 3$ & ${ }^{1} \mathrm{~Pb}-\mathrm{Pb}$ & $\mathrm{zr}$ & Teixeira et al. (2002) \\
\hline Granito Antônio Vicente & - & $1867 \pm 4$ & ${ }^{1} \mathrm{~Pb}-\mathrm{Pb}$ & $\mathrm{zr}$ & Teixeira et al. (2002) \\
\hline Granito Velho Guilherme & - & $1874 \pm 30$ & ${ }^{1} \mathrm{~Pb}-\mathrm{Pb}$ & $\mathrm{rt}$ & Macambira e Lafon (1995) \\
\hline Granito Antônio Vicente & - & $1896 \pm 9$ & ${ }^{1} \mathrm{~Pb}-\mathrm{Pb}$ & $\mathrm{zr}$ & Teixeira et al. (2002) \\
\hline Granito Rio Xingu & - & $1906 \pm 29$ & ${ }^{1} \mathrm{~Pb}-\mathrm{Pb}$ & $\mathrm{zr}$ & Teixeira et al. (2002) \\
\hline
\end{tabular}


Tabela 1. (continuação)

\begin{tabular}{|c|c|c|c|c|c|}
\hline \multicolumn{6}{|c|}{ Suíte Intrusiva Rio Dourado (Mato Grosso) } \\
\hline PT-251 & Sienogranito & $1884 \pm 4 \mathrm{Ma}$ & ${ }^{3} \mathrm{U}-\mathrm{Pb}$ & $\mathrm{zr}$ & Barros et al. (2006) \\
\hline \multicolumn{2}{|c|}{ Grupo Iriri - Serra dos Magalhães } & $1889 \pm 60 \mathrm{Ma}$ & ${ }^{3} \mathrm{U}-\mathrm{Pb}$ & $\mathrm{zr}$ & Pinho et al. (2004) \\
\hline Magmatismo Teles Pires & & $1,78 \mathrm{Ga}$ & & & Pinho et al. (2003) \\
\hline \multicolumn{6}{|c|}{ Granito Serra da Providência } \\
\hline & - & $1606 \pm 24 \mathrm{Ma}$ & $\mathrm{U}-\mathrm{Pb}$ & $\mathrm{zr}$ & Tosdal et al. (1996) \\
\hline & - & $1573 \pm 15 \mathrm{Ma}$ & $\mathrm{U}-\mathrm{Pb}$ & $\mathrm{zr}$ & Bettencourt et al. (1995) \\
\hline & - & $1566 \pm 5 \mathrm{Ma}$ & $\mathrm{U}-\mathrm{Pb}$ & $\mathrm{zr}$ & Bettencourt et al. (1995) \\
\hline & - & $1554 \pm 47 \mathrm{Ma}$ & $\mathrm{U}-\mathrm{Pb}$ & $\mathrm{zr}$ & Tosdal et al. (1996) \\
\hline & - & $1588 \pm 16 \mathrm{Ma}$ & $\mathrm{U}-\mathrm{Pb}$ & $\mathrm{zr}$ & Tassinari et al. (1996) \\
\hline \multicolumn{2}{|l|}{ Batólito Rio Branco } & $1469 \pm 31 \mathrm{Ma}$ & & & Geraldes, Teixeira e Schmus (2000) \\
\hline \multicolumn{2}{|l|}{ Charnoquito Ouro Preto } & $1560 \mathrm{Ma}$ & $\mathrm{U}-\mathrm{Pb}$ & $\mathrm{zr}$ & Bettencourt et al. (1995) \\
\hline Granito Santo Antônio & - & $1406 \pm 32 \mathrm{Ma}$ & $\mathrm{U}-\mathrm{Pb}$ & $\mathrm{zr}$ & Bettencourt et al. (1995) \\
\hline Granito Teotônio & - & $1387 \pm 16 \mathrm{Ma}$ & $\mathrm{U}-\mathrm{Pb}$ & $\mathrm{zr}$ & Bettencourt et al. (1995) \\
\hline Charnoquito Jauru & - & $1351 \pm 8 \mathrm{Ma}$ & $\mathrm{U}-\mathrm{Pb}$ & $\mathrm{zr}$ & Bettencourt et al. (1995) \\
\hline Granito São Lourenço & - & $1314 \pm 13 \mathrm{Ma}$ & $\mathrm{U}-\mathrm{Pb}$ & $\mathrm{zr}$ & Bettencourt et al. (1995) \\
\hline Granito Caripunas & - & $1309 \pm 24 \mathrm{Ma}$ & $\mathrm{U}-\mathrm{Pb}$ & $\mathrm{zr}$ & Bettencourt et al. (1995) \\
\hline Granito Oriente Novo & - & $1080 \pm 27 \mathrm{Ma}$ & $\mathrm{U}-\mathrm{Pb}$ & $\mathrm{zr}$ & Bettencourt et al. (1995) \\
\hline Granito Santa Clara & - & $1081 \pm 50 \mathrm{Ma}$ & $\mathrm{U}-\mathrm{Pb}$ & $\mathrm{zr}$ & Bettencourt et al. (1995) \\
\hline Granito Pedra Branca & - & $990 \pm 5 \mathrm{Ma}$ & $\mathrm{U}-\mathrm{Pb}$ & $\mathrm{zr}$ & Bettencourt et al. (1995) \\
\hline Charnoquito União & - & $1048 \pm 8 \mathrm{Ma}$ & $\mathrm{U}-\mathrm{Pb}$ & $z r$ & Bettencourt et al. (1995) \\
\hline
\end{tabular}

Análises Sm-Nd em rocha total foram realizadas em três amostras. Umas solução traçadora de ${ }^{150} \mathrm{Nd}-{ }^{149} \mathrm{Sm}$ foi adicionada à amostra antes de sua dissolução com ácido fluorídrico e nítrico na proporção de 5:1 em cápsulas Savillex ${ }^{\circledR}$. Após a dissolução e evaporação da amostra, esta foi dissolvida com $7 \mathrm{ml}$ de $\mathrm{HCl} 6 \mathrm{~N}$, e posteriormente com $\mathrm{HCl} 2,5 \mathrm{~N}$. Nd e Sm foram extraídos usando procedimentos convencionais de troca iônica descritos em Patchett e Ruiz (1987) e foram analisados no espectrômetro de massa Finningan MAT-262 com sete coletores. Valores de $\varepsilon_{\mathrm{Nd}}$ foram calculados tomando como base a idade $\mathrm{U}-\mathrm{Pb}$ obtida para a amostra UFMT-18. As idades modelo $\left(\mathrm{T}_{\mathrm{DM}}\right)$ foram calculadas seguindo o modelo de De Paolo (1981).

\section{CONTEXTO GEOTECTÔNICO}

A Província Geocronológica Amazônia Central, porção mais antiga do Craton Amazônico foi dividida por Tassinari e Macambira (1999) em dois domínios, separados pela província Maroni-Itacaiunas. O primeiro domínio é denominado de Bloco Carajás-Iricoumé e o segundo domínio consiste do Bloco Roraima O bloco CarajásIricoumé situa-se na porção central e sul da Província Amazônia Central, leste do Craton Amazônico, alinhando-se segundo a direção NW-SE. Este bloco está dividido em duas áreas: área Carajás e área Xingu-Iricoumé.

A área Carajás é onde o terreno arqueano do Craton Amazônico se encontra mais bem preservado. Representa a província mineral mais importante do Brasil, contendo depósitos de ferro, cobre, ouro, manganês e níquel. Por sua importância econômica é a região mais conhecida do Craton Amazônico. Considera-se que esta área se formou e se estabilizou no Arqueano e foi afetada por evento termal distensivo no Paleoproterozoico, acompanhado de intrusões graníticas, diques máficos e félsicos. A área $\mathrm{Ca}$ rajás está dividida em três domínios tectônicos Terreno Granito-Greenstone Rio Maria, o Cinturão de Cisalhamento Itacaiunas e o Cinturão de Cisalhamento Pau D'Arco, sendo os três domínios, de acordo com a foliação regional, estruturalmente orientados segundo E-W (Tassinari et al., 2000). Vasquez e Rosa-Costa (2008) apresentam uma subdivisão alternativa para a Província Amazônia Central, 
sendo que a área do presente trabalho situa-se entre os dois domínios propostos: Iriri-Xingú a oeste e Santana do Araguaia a leste. Nessa subdivisão os autores delimitam o terreno arqueano sem nenhuma evidência de retrabalhamento paleoproterozoico, mais ao norte e o nomeiam de Domínio Rio Maria. Consideram que o Domínio Santana do Araguaia compreende rochas paleoproterozoicas com evidências de retrabalhamento. As coberturas vulcano-plutônicas de idade orosiriana, além das coberturas sedimentares de rifts, são inseridas no domínio Iriri-Xingu.

Neste artigo, entretanto, utilizamos a divisão proposta por Tassinari e Macambira (1999) e (Tassinari et al., 2000) conforme Figura 1, por ser a mais amplamente utilizada tanto na literatura nacional como internacional.

O plúton granitoide mais antigo da área Xingu-Iricoumé, incluindo o Domínio Rio Maria de Vasquez, Macambira e Armstrong (2008) é o Monzogranito Água Branca de composição cálcico-alcalina e idade 1,96 a 1,91 Ga (Santos e Reis Neto, 1982; João, Santos, Provost, 1985; Almeida, Macambira, Scheller, 1997). Adicionalmente existem alguns corpos situados próximo ao rio Xingu, incluídos na Suíte Granítica Parauari, com idade de 1,92 Ga (Macambira, 1992). O Supergrupo Uatumã (Santos e Reis Neto, 1982) é composto de rochas vulcânicas e plutônicas que variam de intermediárias a félsicas. No norte e nordeste da Província Amazônia Central foram denominadas Grupo Mapuera e Iricoumé e a sudeste são incluídas no Grupo Iriri, Maloquinha, enquanto na porção sul são denominadas de Iriri e Rio Dourado. Nas proximidades dos rios Tapajós e Jamanxim, Dall'Agnol, Silva e Scheller (1996) e Moura, Gorayeb e Matsuda (1999) evidenciam que os riolitos do Grupo Iriri tem idades de cristalização em torno de 1,88 Ga. Pinho et al. (2004) apresentam idades U-Pb em zircão de 1,89 Ma, para vulcânicas do Grupo Iriri localizadas na Serra de Magalhães extremo sul da Área Xingu-Iricoumé.

Dall'Agnol, Lafon e Macambira (1994) interpretaram os granitos alcalinos a subalcalinos expostos em toda a área Xingu-Iricoumé como do tipo-A, rapakivi de ambiente anorogênico. No domínio mais a norte, na região do Pitinga, alguns corpos um pouco mais jovens $(1,82 \mathrm{Ga})$ são altamente mineralizados em Sn (Granito Madeira) e estão intrusivos no Grupo Iricoumé (Costi, Dall'Agnol, Moura, 2000).

Vasquez et al. (1999), Lamarão et al. (1999) definiram através de dados geoquímicos do Supergrupo Uatumã e granito Parauari, dois eventos vulcano-plutônico de idade Paleoproterozoica. O mais novo de 1,89 - 1,88 Ga de caráter subalcalino e o mais antigo de 2,0 - 1,98 Ga de caráter cálcico-alcalino.

A geologia da área de estudo (Figura 2) é constituída de um embasamento de granitos da Suíte Intrusiva Vila Rica (SIVR), cortados pela Suíte Intrusiva Rio Dourado (SIRD), por rochas máficas e ultramáficas (lamprófiros e gabros acamadados), recoberta por rochas supracrustais do Grupo Iriri (GI). A SIVR foi desmembrada do complexo granítico-gnáissico-anfibolítico (CGA) por Lacerda et al. (2004), com base apenas na intensidade de deformação. Rochas menos deformadas foram agrupadas na SIVR enquanto as que apresentam evidências de mais de uma fase de deformação foram deixadas como embasamento. Usando o critério de Lacerda et al. (2004) amostras das porções mas deformadas e menos deformadas foram selecionadas e datadas por Barros et al. (2009). Os resultados apresentaram idade U-Pb de 1,96 Ga, tanto para o domínio deformado como para o domínio menos deformado dos granitos indicando que a extensão da Suíte Intrusiva Vila Rica é bem maior do que $100 \mathrm{~km}^{2}$ caracterizando um batólito com variações na intensidade de deformação.

\section{GEOLOGIA E PETROGRAFIA}

\section{Suíte Intrusiva Rio Dourado (SIRD)}

A SIRD foi descrita a primeira vez por Cunha et al. (1980), durante o mapeamento geológico da folha Tocantins (SC.22) - Projeto Radam Brasil. Durante o projeto, sessenta corpos intrusivos foram mapeados como granodioritos, dioritos, granófiros, microganitos e adamelitos em íntima associação co-magmática com as vulcânicas da Formação Iriri. Cunha et al. (1980) englobam a SIRD no Supergrupo Uatumã. Os autores em questão apresentam na análise modal uma predominância de composições sienograníticas e monzograníticas. Em termos mineralógicos, descrevem feldspato potássico pertítico, plagioclásio, quartzo e biotita e como componentes máficos menos frequente citam hornblenda e clorita. Como minerais acessórios descrevem apatita e opacos e raramente fluorita e zircão.

As primeiras datações realizadas para os granitos da SIRD foram feitas pelo método Rb-Sr (Cunha et al., 1980) e os dados analíticos se alinharam segundo duas retas isocrônicas: uma com idade de $1737 \pm 50$ Ma e razão inicial ${ }^{87} \mathrm{Sr} /{ }^{86} \mathrm{Sr}$ de $0,719 \pm 0,008$ e outra de $1641 \pm 22$ Ma e razão inicial ${ }^{87} \mathrm{Sr} /{ }^{86} \mathrm{Sr}$ de $0,703 \pm 0,0003$. Na época os autores atribuíram a primeira idade como referente à SIRD e a segunda como da Suíte Intrusiva Tarumã, sendo esta última mais jovem que a Formação Gorotire.

A SIRD ocorre associada com as rochas vulcânicas do GI. Análises U-Pb em zircão pelos métodos de diluição isotópica publicadas por Barros et al. (2006) e Barros et al. (2008) indicam uma idade de 1,88 Ga para tais rochas, similares a outros granitos e vulcânicas associadas do tipo A do Craton Amazônico (ver Tabela 1). Uma cobertura sedimentar denominada por Cunha et al. (1980) como Formação Gorotire ocorre na porção sul da área. 
A geologia da área estudada é apresentada na Figura 2. Os corpos que constituem a SIRD edificam serras alongadas, morros e colinas suaves e afloram em blocos e matacões (Figura 3A). As rochas da SIRD são de coloração rosa-avermelhado a rosa-claro, predominantemente maciças, embora porções levemente foliadas sejam observadas; a textura é equigranular com ocorrências raras de fácies porfiríticas, granulação média a grossa, sendo muito comum a presença de textura rapakivi e enclaves ricos em minerais máficos (Figuras 3B e 3C). A SIRD é cortada por veios de quartzo em várias direções e contém xenólitos de rochas mais antigas (Figura 3D), representadas principalmente por rochas máficas e mesocráticas. Um afloramento em especial apresenta um número expressivo de xenólitos de tamanhos e composições variadas $(10$ a $50 \mathrm{~cm}$ ), sendo que a maioria destes, apresentam bordas corroídas por processos de assimilação (Figura 3E).

Rochas gabroicas com textura lamprofírica (Figura 3F) (Rocha e Barros, 2010) e olivina gabros com acamamento rítmico (inédito) foram recentemente reconhecidos na região. Domo de composição andesítica nas proximidades da Fazenda Sonho Meu apresenta feições de mistura de magma (Figura 3G). A Idade desses andesitos $(1,87 \mathrm{Ga})$ (inédita) sugere cogeneticidade com o a Suíte Intrusiva Rio Dourado. Diques de aplito (quartzo e feldspato potássico de granulação fina e textura sacaroide) cortam os granitos e as rochas gabroicas (3I) e apresentam espessura variando de 3 a $25 \mathrm{~cm}$.

Utilizando a classificação de Streckeisen (1976), as rochas da SIRD mostram composição predominantemente sienogranítica com uma pequena variação para monzogranítica.

Petrograficamente os granitos da SIRD, podem ser divididos em três tipos: biotita granito, biotita granito com anfibólio e granito granofírico.

O biotita granito e o biotita granito com anfibólio possuem granulação média a grossa, variando de 1 a $7 \mathrm{~mm}$, textura inequigranular a porfirítica, xenomórfica a hipidiomórfica, constituídos essencialmente de feldspato alcalino pertítico, quartzo, plagioclásio, tendo como minerais máficos, biotita e, em alguns casos, anfibólio. Ocorrem como minerais acessório titanita, allanita, zircão e apatita e como minerais secundários clorita, muscovita, epidoto e opacos. As variedades que contem anfibólio apresentam em geral maior conteúdo de titanita como acessório.

O feldspato alcalino ocorre como cristais anédricos a subédricos, com geminação em grade e mais raramente com geminação Carlsbad sendo ambos pertíticos com o plagioclásio sódico ocorrendo em filme e ás vezes em grãos. Inclui agulhas de apatita e, mais raramente, cristais de quartzo cuneiformes caracterizando uma textura gráfica. O plagioclásio, representado pelo oligoclásio, ocor- re em cristais subédricos tabulares contendo geminações polissintéticas do tipo albita e periclina, ocorrendo muitas vezes como auréola nos cristais de K-feldspato evidenciando uma textura rapakivi. Há indícios incipientes de alteração hidrotermal do tipo sericitização no feldspato potássico e saussuritização no plagioclásio. O quartzo apresenta-se essencialmente de forma anédrica ou intercrescido junto com o feldspato potássico (textura gráfica) apresentando às vezes extinção ondulante. $\mathrm{O}$ anfibólio, quando presente ocorre em prismas euédricos a cristais anédricos, com pleocroísmo verde-amarelado a verde-oliva (hornblenda). Interdigitações com biotita ocorrem localmente bem como inclusões de titanita. A biotita forma cristais lamelares, com pleocroísmo de castanho a marrom-avermelhado e está associada com minerais opacos. Contém inclusões de cristais prismáticos alongados de zircão de até $0,5 \mathrm{~mm}$ assim como, as vezes inclusões de titanita. A titanita ocorre em cristais euédricos a anédricos, cor marrom-clara, relevo forte e alta birrefrigência. A apatita geralmente está inclusa no plagioclásio e $\mathrm{K}$-feldspato, aparece em cristais prismáticos alongados, incolores. A Allanita exibe formas tabulares, com tamanhos de até $1,5 \mathrm{~mm}$, coloração marrom-amarelada, zonada e contendo inclusões de opacos. Como produto de alteração hidrotermal aparece epidoto associado com allanita, muscovita, clorita e opacos. O fácies granofírico apresenta coloração rosa esbranquiçada, granulação grossa a média e situa-se em locais com feições circulares na imagem de satélite. A composição mineralógica é essencialmente de quartzo e feldspato potássico com pequena proporção de biotita. O plagioclásio predomina como lamelas de ex-solução que compõem o intercrescimento pertítico.

\section{GEOQUÍMICA}

Análises representativas da Suíte Intrusiva Rio Dourado são apresentadas na Tabela 2.

Para classificar os granitos com relação a sua afinidade geoquímica foram utilizados diagramas propostos por Patiño Douce (1997) e Frost et al. (2001). Aplicando os diagramas binários que separam rochas de afinidade cálcico-alcalina de rochas de afinidade alcalina (tipo A) $\left(\mathrm{CaO}+\mathrm{Al}_{2} \mathrm{O}_{3}\right)$ ou apenas $\mathrm{Al}_{2} \mathrm{O}_{3}$ vs. $\mathrm{Ca} /(\mathrm{FeO}+\mathrm{MgO}+\mathrm{TiO} 2)$, as amostras da SIRD plotam no campo dos granitos tipo A (Figura 4A). Patiño Douce (1997) e Frost et al. (2001) desenvolveram diagramas específicos para granitos do tipo A, usando razões entre os elementos maiores para separar granitos oxidados dos reduzidos. Os campos propostos por estes autores superpõem-se em parte. Os granitos da SIRD plotam nesse campo de superposição no entanto não apresentam características de granitos reduzidos. Dall'Agnol e Oliveira (2007) apresentam resultados dos granitos tipo A 


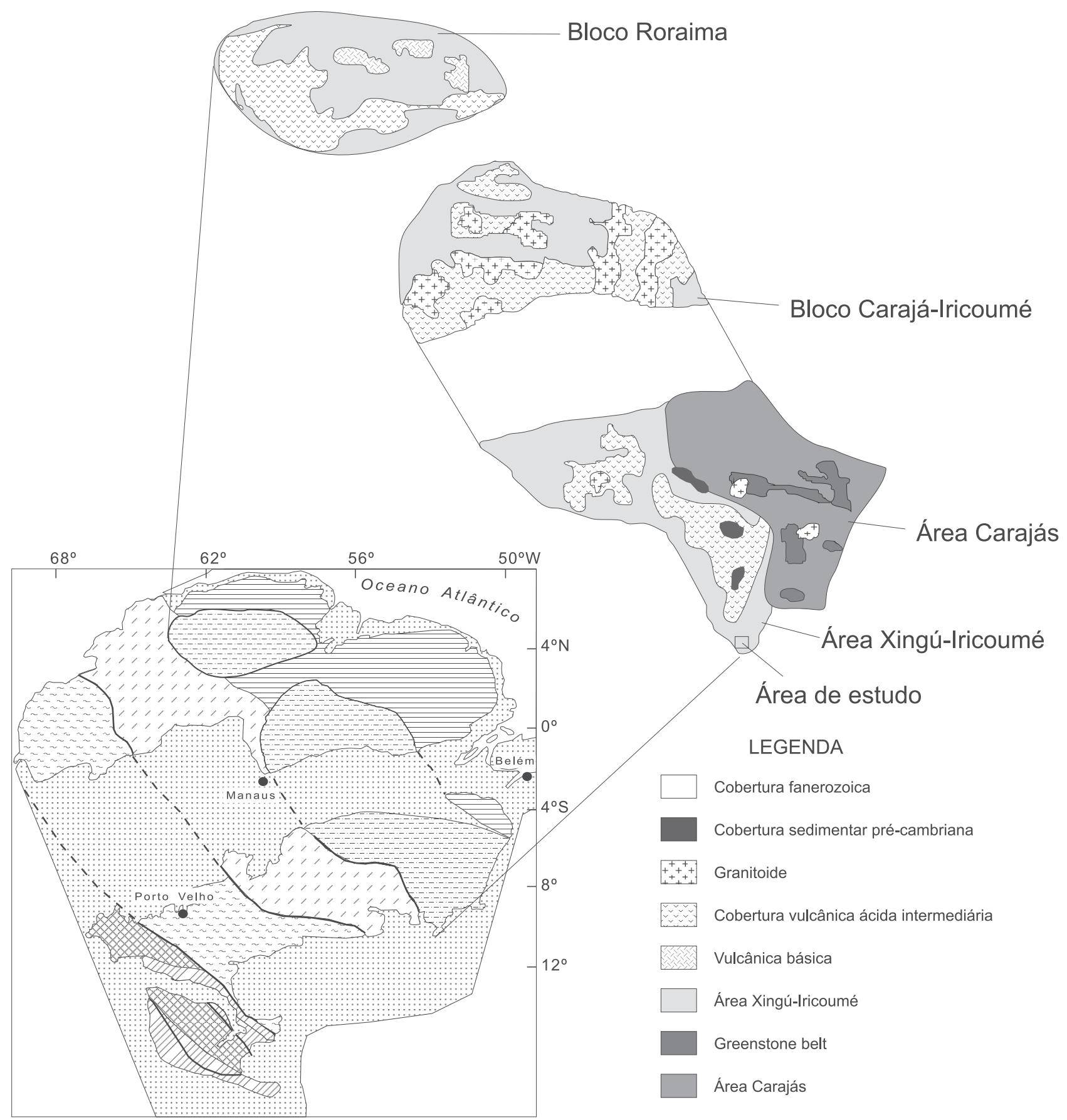

PROVINNCIAS GEOCRONOLÓGICAS

Amazônia Central

$>2,3 \mathrm{Ga}$

$\sim$ Rio Negro - Juruena

$1,8-1,55 \mathrm{Ga}$

2,2 - 1,9 Ga

80 Rondoniano - San Ignácio

Ventuari - Tapajós

$1,9-1,8 \mathrm{Ga}$

$1,55-1,3 \mathrm{Ga}$

QUA Sunsás

Cobertura fanerozoica

$1,25-1,0 \mathrm{Ga}$

Figura 1. Mapa com as províncias geocronológicas do Craton Amazônico, modificado a partir de Tassinari e Macambira (1999). 


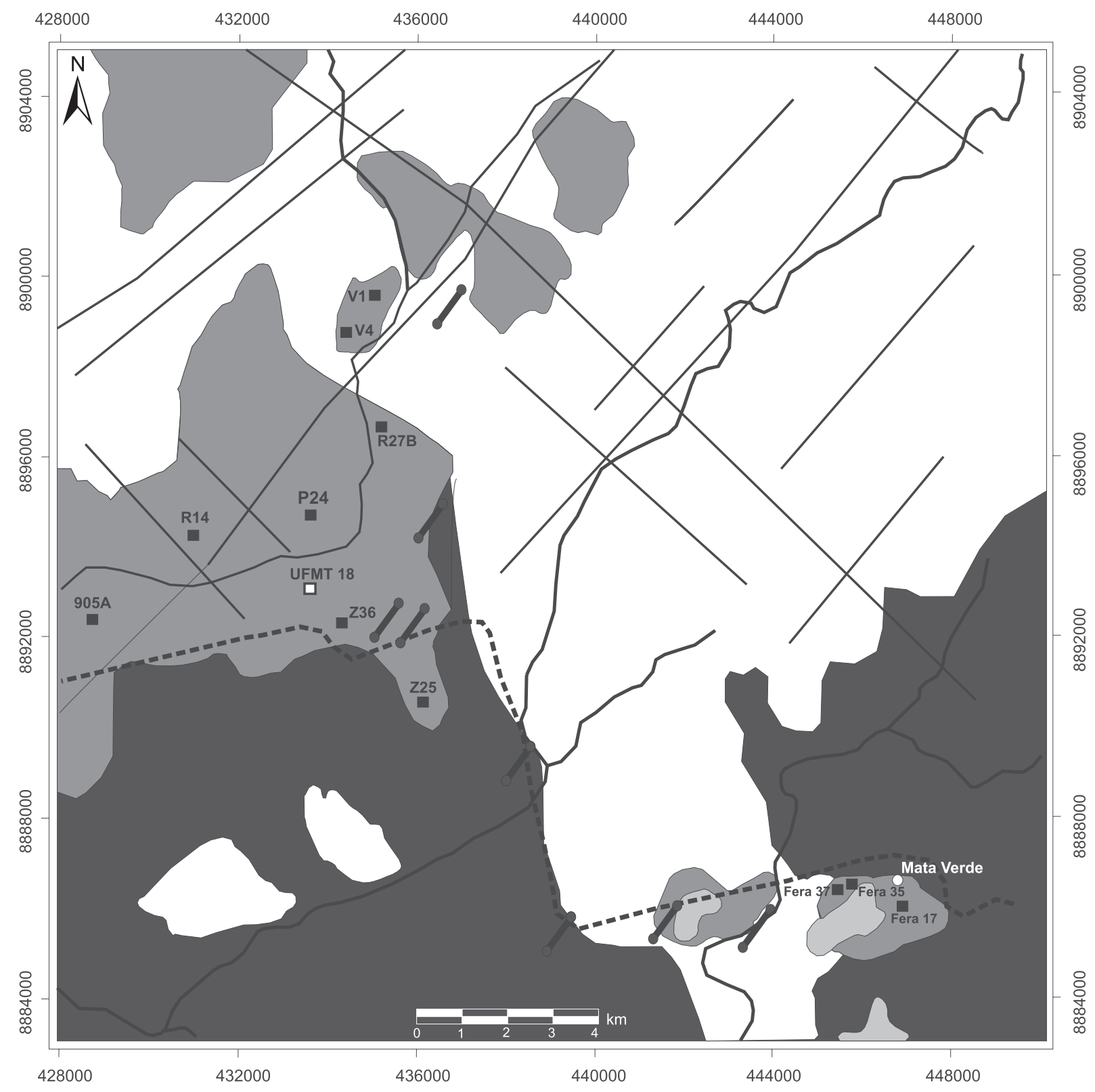

Legenda

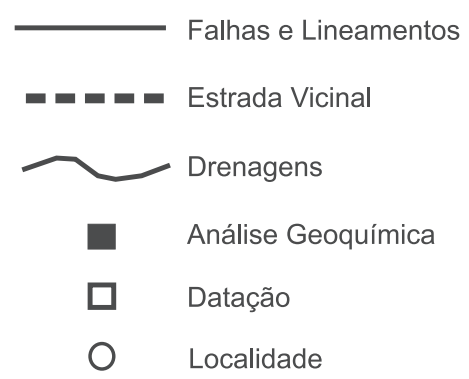

Litologias

$\square$ Grupo Iriri $\square$ Suíte Intrusiva Rio Dourado

Diques de diabásio/
Subvulcânica ácida

Lamprófiros e gabros acamadados

Suíte Intrusiva Vila Rica

GCS - South American 1969

Datum WGS 84 - Zona 22 Sul

Figura 2. Mapa Geológico da área de estudo. 

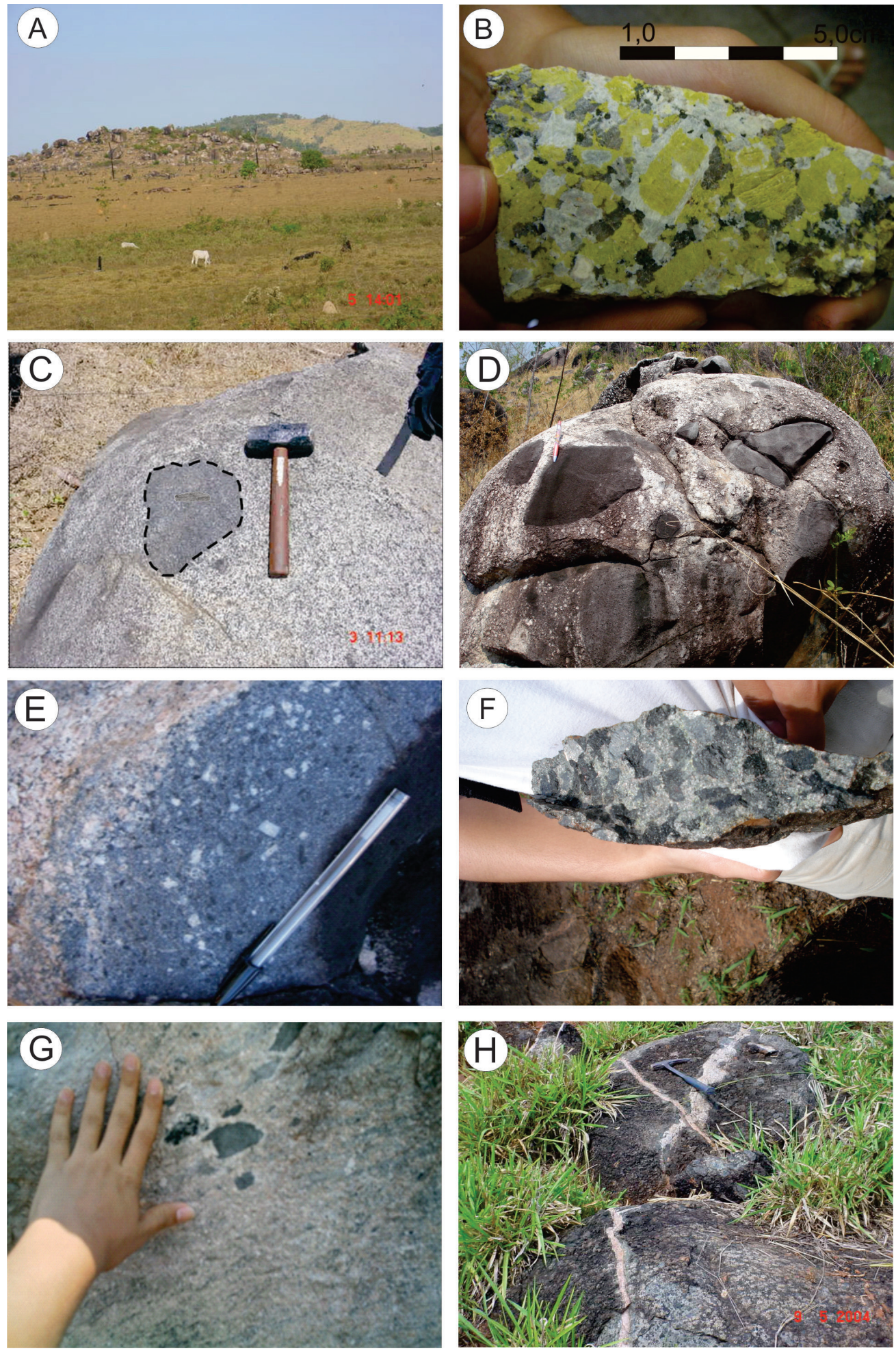

Figura 3. A. Forma de Ocorrência em campo dos Granitos da SIRD. B. Detalhe de amostra da SIRD exibindo textura rapakivi. C. Enclave máfico em granito da SIRD. D. Xenólitos de rochas máficas no granito da SIRD. E. Evidências de assimilação parcial de xenólitos pelo magma granítico. F. Hornblendas evédricas em amostra de Lamprófiro. G. Mistura de magma diorítico e riolítico em domo andesítico do GI. H. Diques de aplito cortando Lamprófiro. 


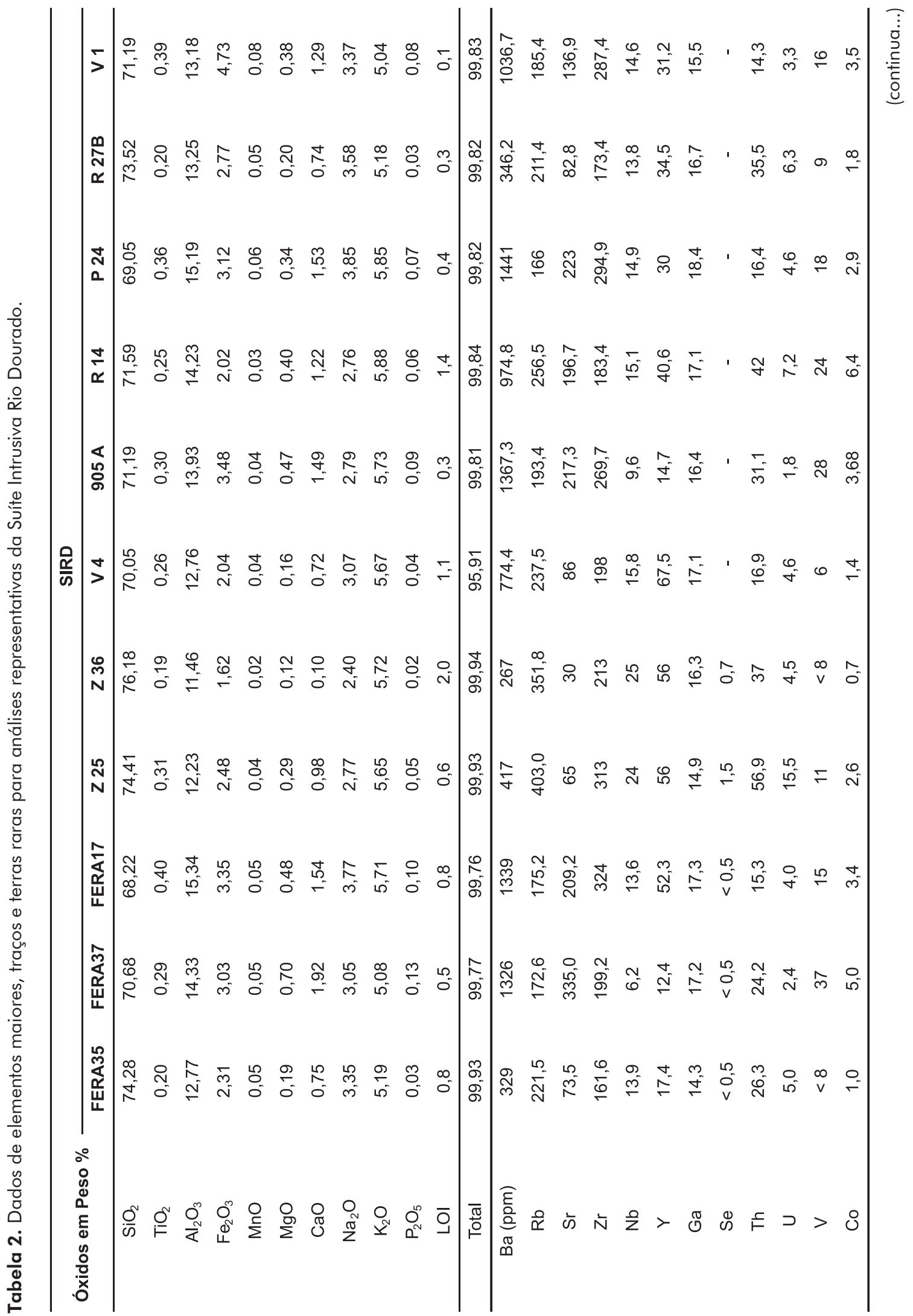




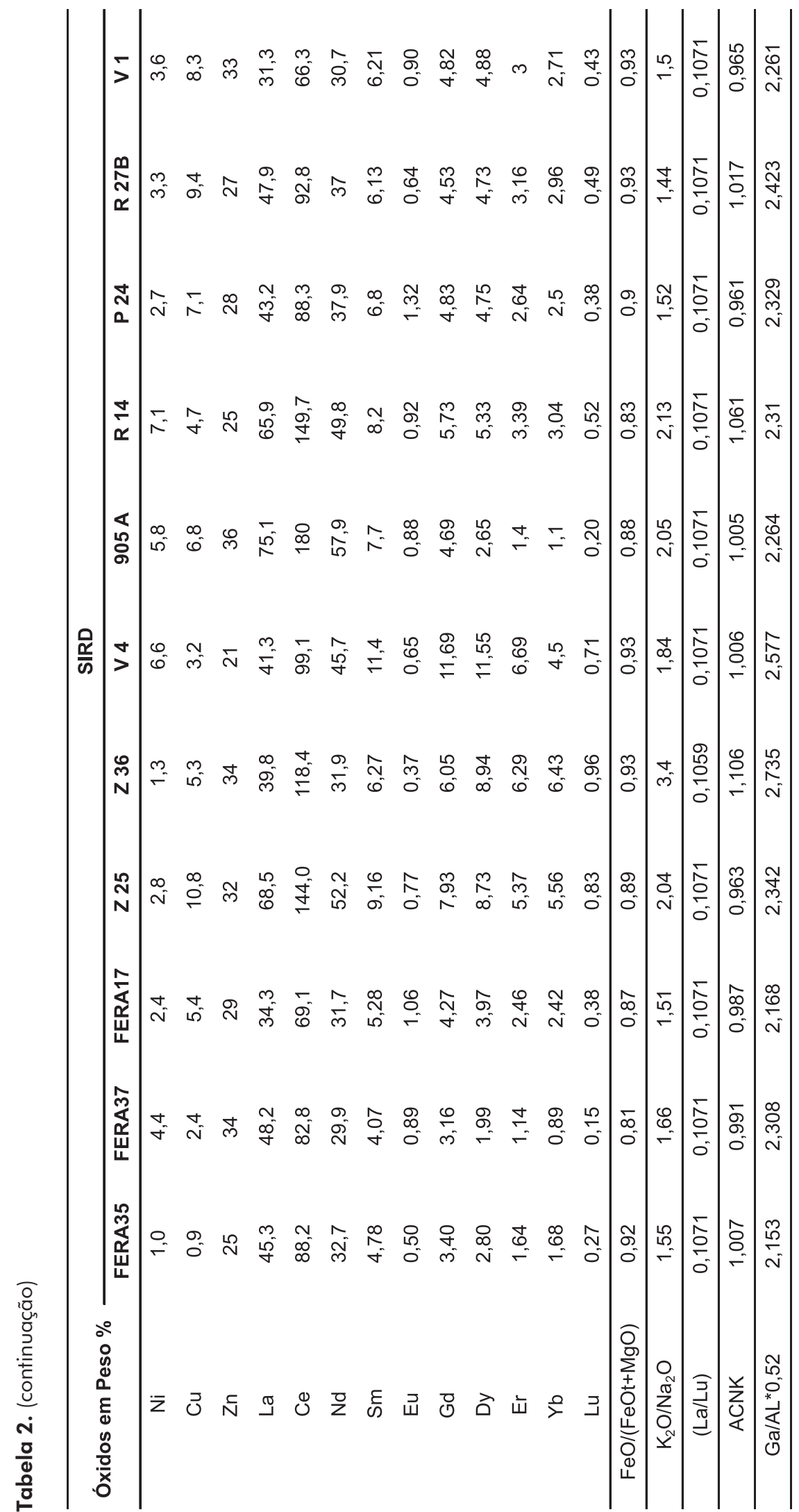



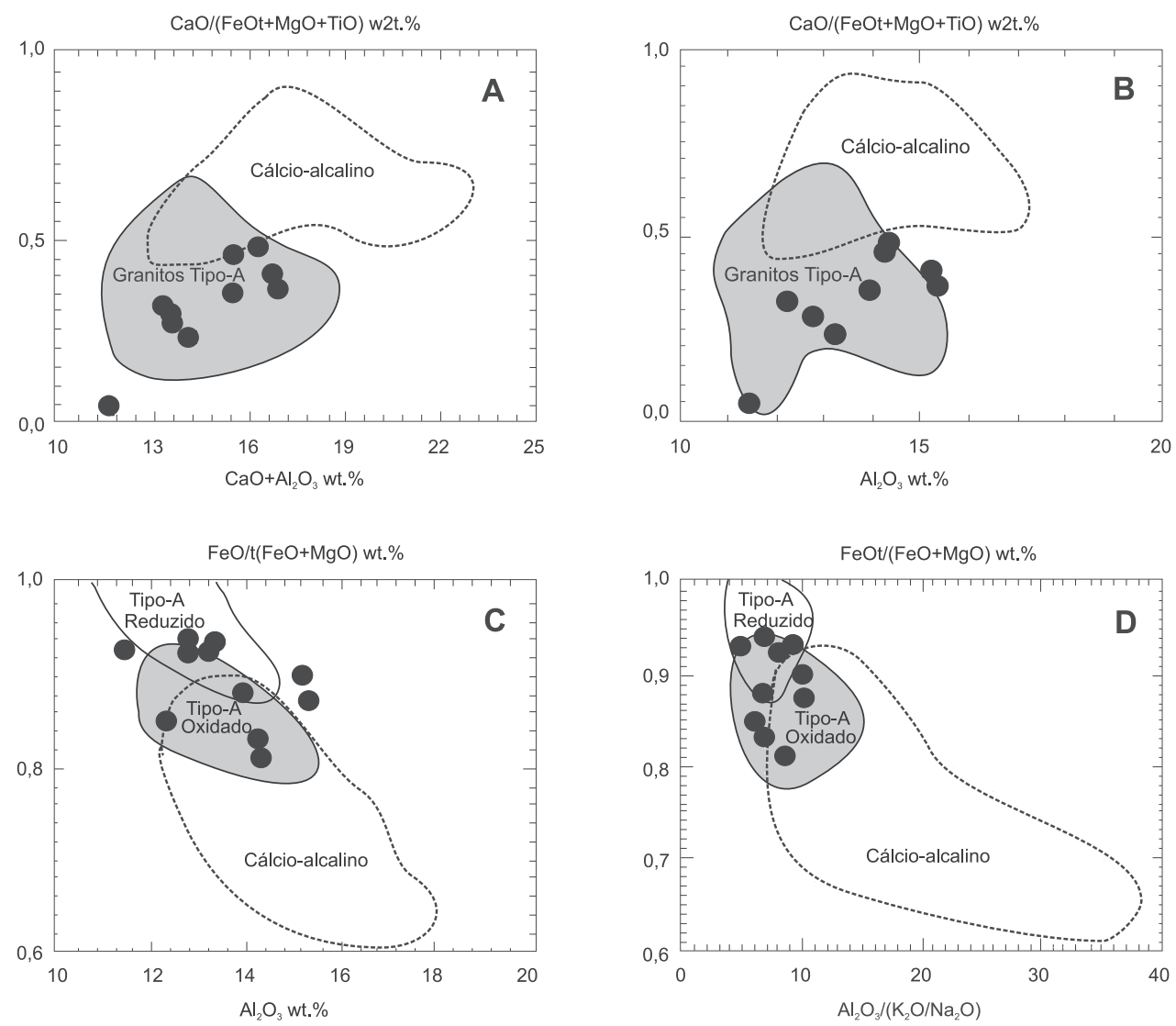

Figura 4. Diagramas mostrando composições de rocha total de granitos da SIRD, comparados aos campos de granitos alcalinos oxidados e reduzidos anorogênicos da Província Amazônia Central (dados de Dall'Agnol e Oliveira, 2007). Os campos determinados como cálcico-alcalinos são baseados em dados de granitoides da Sierra Nevada e Tuolumne (Frost et al., 2001): A. $\left.\mathrm{CaO} / \mathrm{FeO}_{+}+\mathrm{MgO}+\mathrm{TiO}_{2}\right)$ vs. $\mathrm{CaO}+\mathrm{Al}_{2} \mathrm{O}_{3} ;$ B. $\mathrm{CaO} / \mathrm{FeO}+\mathrm{MgO}+\mathrm{TiO}_{2}$ ) vs. $\mathrm{Al}_{2} \mathrm{O}_{3}$; C. $\mathrm{FeO}_{\mathrm{t}} /\left(\mathrm{FeO}_{\mathrm{f}}+\mathrm{MgO}\right)$ vs. $\mathrm{Al}_{2} \mathrm{O}_{3} ;$ D. $\mathrm{FeO}_{\mathrm{t}} /\left(\mathrm{FeO}_{\mathrm{f}}+\mathrm{MgO}\right)$ vs. $\mathrm{Al}_{2} \mathrm{O}_{3} /\left(\mathrm{K}_{2} \mathrm{O} / \mathrm{Na}_{2} \mathrm{O}\right)$.

da Serra dos Carajás, Velho Guilherme e Jamon e compara-os com os Granitos Rapakivi da Finlândia usando diagrama $\mathrm{SiO}_{2}$ vs. $\mathrm{K}_{2} \mathrm{O}+\mathrm{Na}_{2} \mathrm{O}$. Amostras da SIRD ocupam o mesmo campo das amostras estudadas por Dall'Agnol e Oliveira (2007) e assemelham-se principalmente a Suíte Jamon (Figura 5). Com relação à saturação em alumina de acordo com os índices de Shand em sua forma modificada por Maniar e Piccoli (1989) as rochas da SIRD são levemente peraluminosas com índices de ACNK entre 0,9 e 1 (ver Tabela 2).

O padrão de elementos terras raras normalizados para condritos apresentado pela SIRD (Figura 6) é similar àqueles apresentados para outros granitos tipo $\mathrm{A}$ do Craton Amazônico como os Granitos Musa, Jamon e Cigano (Dall'Agnol et al., 1999a) mostrando ligeiro enrique- cimento de elementos terras raras leves em relação aos pesados, pronunciada anomalia negativa de Eu e padrão horizontalizado dos elementos terras raras pesados. Os teores de elementos traços quando plotados em diagrama multielementar normalizados para condritos (Figura 7) mostra enriquecimento em $\mathrm{K}_{2} \mathrm{O}, \mathrm{Rb}$, Ba e $\mathrm{Th}$, anomalia negativa de $\mathrm{Ta}$ e $\mathrm{Nb}$ e empobrecimento de $\mathrm{Sm}, \mathrm{Y}, \mathrm{Yb}$.

Saunders, Tarney e Weaver (1980), consideram que fluidos de zona de subducção apresentam anomalia negativas de $\mathrm{Ta}$ e Nb, se ficarem retidos na crosta oceânica subductada, em minerais titaníferos tais como ilmenita, rutilo ou titanita. Dessa forma, em ambientes pós-colisionais, as anomalias negativas de Ta e $\mathrm{Nb}$ são atribuídas à fusão de crosta litosférica produzida previamente em zona de subducção. Uma hipótese alternativa para o empobrecimen- 
to em terras raras pesados é a fusão parcial de uma rocha contendo granada e piroxênio que permaneceram na fonte como resíduo de fusão parcial. Este magma pobre em terras raras pesados evolui para composições mais ácidas por cristalização fracionada e contaminação crustal.

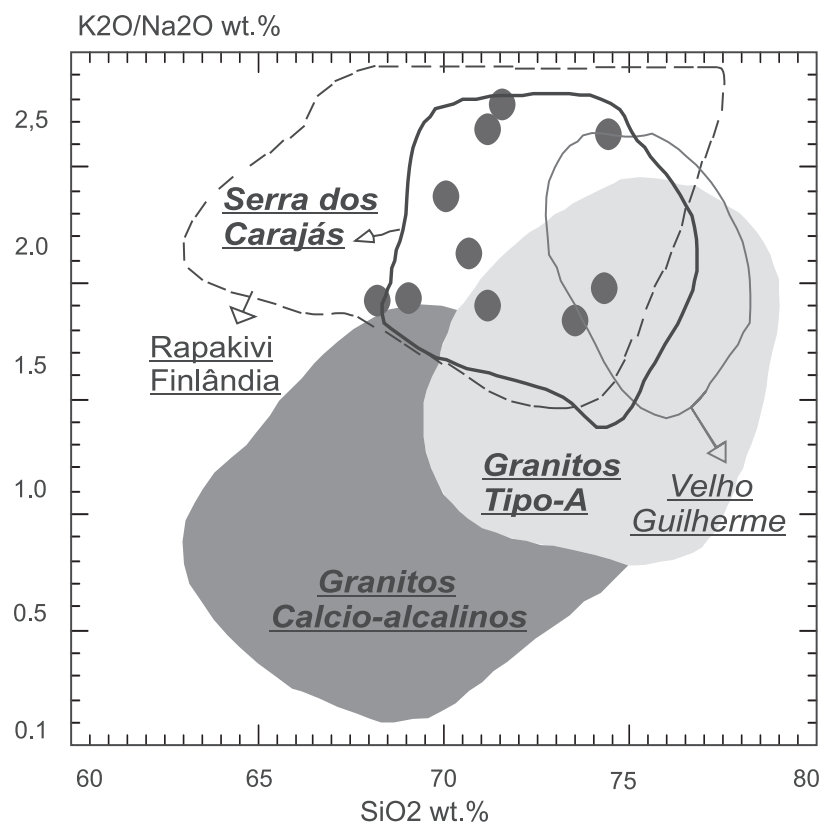

Figura 5. Diagrama $\mathrm{K}_{2} \mathrm{O} / \mathrm{Na}_{2} \mathrm{O}$ vs. $\mathrm{SiO}_{2}$ mostrando as composições em rocha total dos granitos da SIRD comparados aos campos propostos por Patiño Douce (1997) e campos dos Granitos tipo A da Finlândia, Serra dos Carajás e Velho Guilherme.

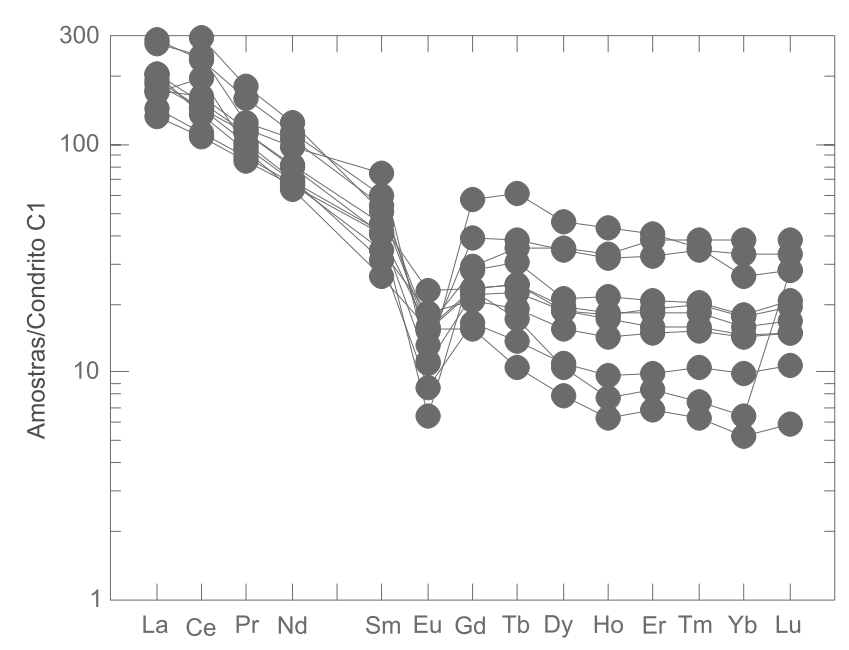

Figura 6. Padrão de Elementos Terras Raras normalizados para Condritos dos Granitos da SIRD.
Amostras dos granitos da SIRD plotadas em diagramas $\mathrm{Rb} v s$. $\mathrm{Y}+\mathrm{Nb}$ propostos por Pearce (1996) para discriminação de ambientes tectônicos, indicam ambiente pós-colisional a anorogênico para estas rochas (Figura 8). Eby (1992) propõe que os granitos tipo A originados em ambientes anorogênicos, apresentam valores de $\mathrm{Y} / \mathrm{Nb}$ inferiores a 1,2 e são de origem mantélica. Por outro lado granitos tipo A originados em outros ambientes tectônicos com fontes crustais, podem ser definidos pelas razões $\mathrm{Y} / \mathrm{Nb}$ acima de 1,2. Os granitos da SIRD (Figura 9) plotam no campo dos granitos tipo A2 transicionando para o tipo A1. Estes resultados são concordantes com ambiente pós-colisional.

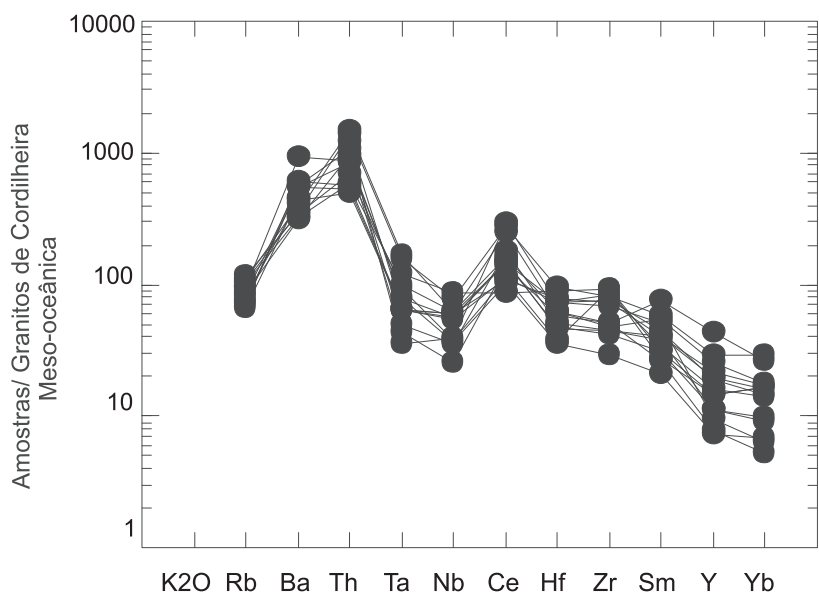

Figura 7. Diagrama multielementar normalizado para os condritos apresentando os teores de elementos traços dos granitos da SIRD.

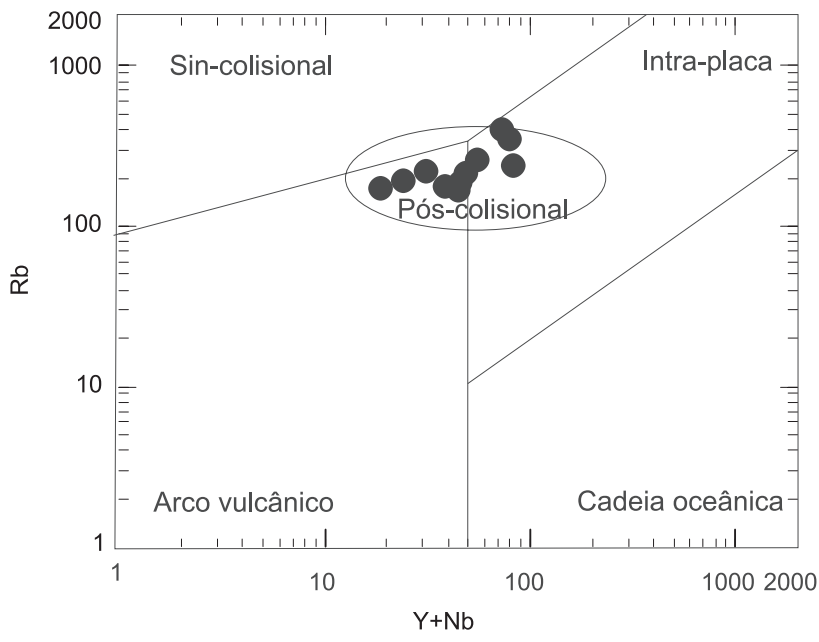

Figura 8. Amostras da SIRD plotadas em diagrama discriminante de ambiente tectônico de Pearce et al. (1984). 


\section{RESULTADOS ISOTÓPICOS}

Os resultados isotópicos $\mathrm{U}-\mathrm{Pb}$ são apresentados na Tabela 2 e os de Sm-Nd na Tabela 3.

A idade obtida para a amostra UFMT-18 pelo método U-Pb em zircão é de $1876 \pm 39 \mathrm{Ma}$ similar a datada anteriormente por Barros et al. (2006) para PT-251
$1884 \pm 4 \mathrm{Ma}$. Assim a idade de cristalização da rocha é considerada em torno de 1,88 Ga. O diagrama concórdia da UFMT-18 é mostrado na Figura 10. Os dados de residência crustal (TDm) entre 2,62 a 2,84 (Tabela 4) e os valores negativos de $\varepsilon_{\mathrm{Nd}}$ variando de -3 a -10 indicam que a Suíte Intrusiva Rio Dourado formou-se a partir de refusão de crosta mais antiga, possivelmente arqueana.
A

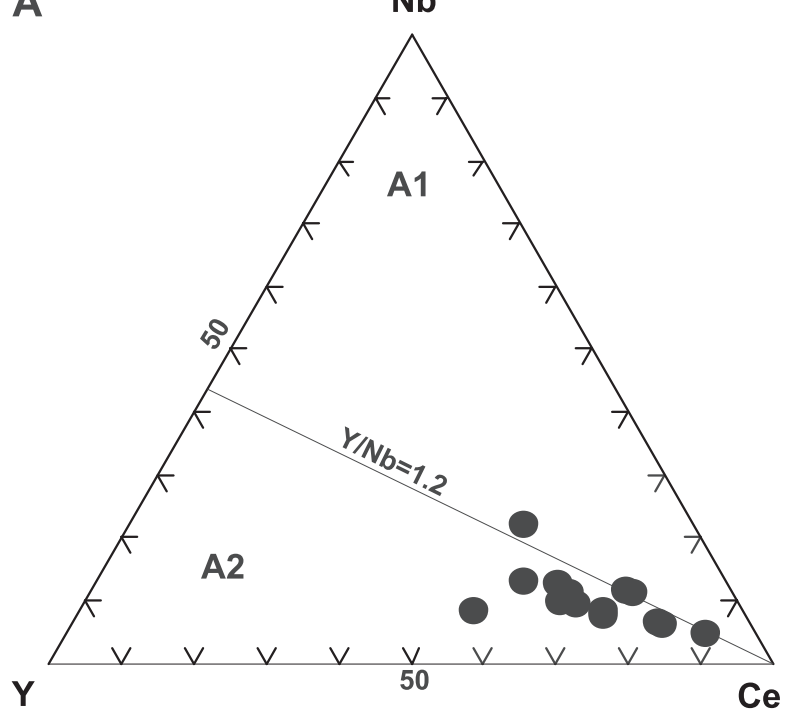

B

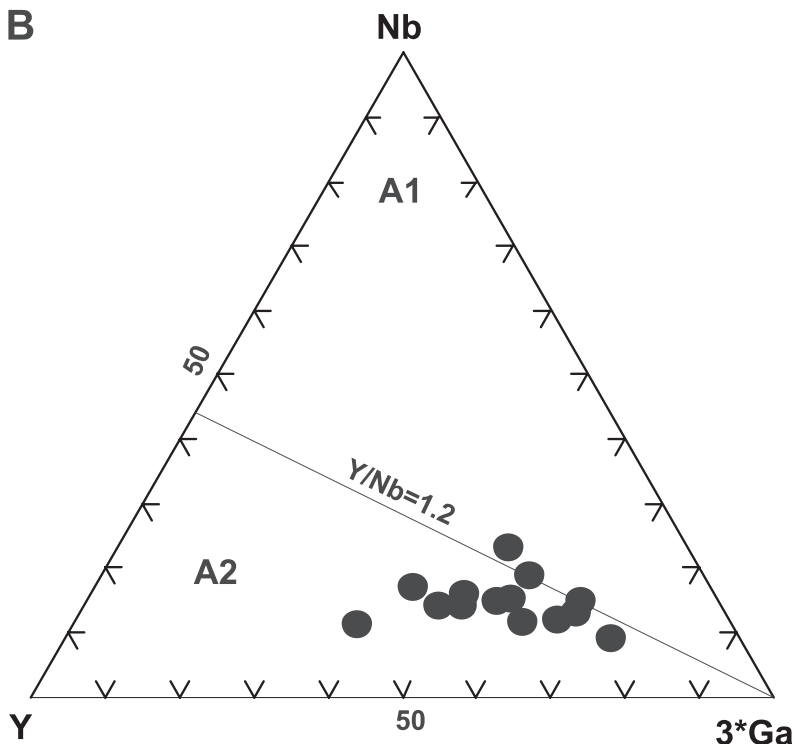

Figura 9. Amostras da SIRD plotadas em diagramas propostos por Eby (1992) para discriminar granitos tipo A1 (originados de plumas ou zonas de rift continental em ambiente anorogênico) de tipo A2 (outros ambientes tectônicos, incluindo pós-colisional relacionados a fusões crustais).

Tabela 3. Resultados isotópicos U-Pb para amostras representativas da Suíte Intrusiva Rio Dourado.

\begin{tabular}{lcccccc}
\hline & ${ }^{235} \mathbf{U} /{ }^{207} \mathbf{P b}$ & $(\mathbf{p c t})$ & ${ }^{238} \mathbf{U} /{ }^{206} \mathbf{P b}$ & (pct) & Coeficiente de Correção & ${ }^{206} \mathrm{~Pb} /{ }^{207} \mathrm{~Pb}$ \\
\hline Zircão 01 & 3,92791 & 0,590 & 0,250272 & 0,585 & 0,9883 & 0,113828 \\
Zircão 02 & 3,34407 & 0,881 & 0,213427 & 0,877 & 0,99153 & 0,113639 \\
Zircão 03 & 4,9559 & 0,827 & 0,314889 & 0,826 & 0,994104 & 0,114149 \\
Zircão 04 & 4,61685 & 0,612 & 0,290794 & 0,606 & 0,98584 & 0,115149 \\
\hline
\end{tabular}

Tabela 4. Resultados isotópicos Sm-Nd para amostras representativas da Suíte Intrusiva Rio Dourado.

\begin{tabular}{|c|c|c|c|c|c|c|c|}
\hline Amostra da SIRD & Sm (ppm) & Nd (ppm) & ${ }^{147} \mathrm{Sm} /{ }^{144} \mathrm{Nd}$ & ${ }^{143} \mathrm{Nd} /{ }^{144} \mathrm{Nd}( \pm 2 \mathrm{SE})$ & $\varepsilon_{\mathrm{Nd}(0)}$ & $\mathrm{T}_{\mathrm{DM}}(\mathrm{Ga})$ & $\varepsilon_{\mathrm{Nd}}(1,88 \mathrm{Ga})$ \\
\hline Fera 14 & 5,428 & 23,415 & 0,1401 & $0,511781+/-14$ & $-16,72$ & 2,62 & $-3,10$ \\
\hline Fera 45 & 10,010 & 63,457 & 0,0954 & $0,510839+/-15$ & $-35,09$ & 2,84 & $-10,7$ \\
\hline Fera 51 & 7,462 & 50,110 & 0,0900 & $0,510921+/-12$ & $-33,50$ & 2,61 & $-7,81$ \\
\hline
\end{tabular}




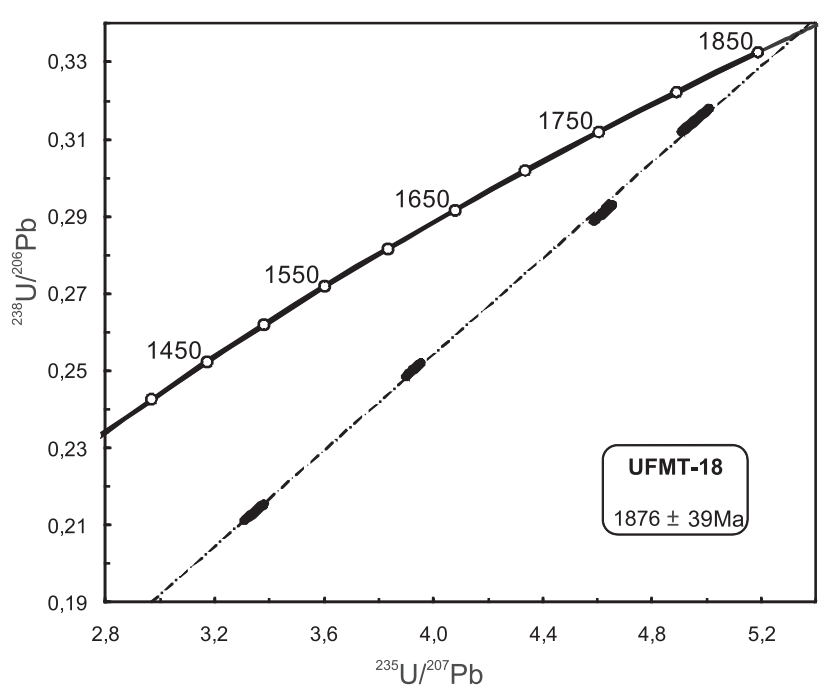

Figura 10. Diagrama concórdia $\mathrm{U}-\mathrm{Pb}$ para a amostra UFMT-18 da SIRD mostrando idade de $1876 \pm 39 \mathrm{Ma}$, próxima à idade da amostra PT-251 de Barros et al. (2006), que é de $1884 \pm 4$ Ma.

\section{CONCLUSÕES E SUGESTÕES}

A Suíte Intrusiva Rio Dourado apresenta três tipos petrográficos: biotita-granito, biotita-granito com anfibólio e granito granofírico, todos apresentando caráter levemente peraluminoso. Os teores de $\mathrm{Al}_{2} \mathrm{O}_{3}$ são um pouco mais elevados do que os granitos tipo A oxidados estudados por Dall'Agnol et al. (1999a, 1999b) e Dall'Agnol e Oliveira (2007), fazendo com que algumas amostras caiam fora dos campos propostos, por estes autores. Esse fato exige estudos estatísticos adicionais nas características geoquímicas de granitos tipo A.

As razões de $\mathrm{FeO} / \mathrm{FeO}+\mathrm{MgO}$ entre 0,8 e 0,95 indicam afinidade com granitos do tipo A oxidados para estas rochas. Teores de $\mathrm{CaO}$ são baixos como esperado nos granitos tipo A. Padrões de Elementos Terras Raras são marcados por enriquecimento de elementos terras raras leves sobre pesados e anomalia negativa de Eu, assemelhando-se aos padrões apresentados por Dall'Agnol et al. (2005) para outros granitos tipo A do Craton Amazônico (Jamon, Serra dos Carajás, Cigano e Musa). Diferenciam-se dos padrões dos Granitos Vicente e Velho Guilherme que apresentam menor fracionamento de elementos terras raras pesados. Elementos traços mostram anomalia de $\mathrm{Nb}$ e $\mathrm{Y}$ interpretadas como herança de uma fonte previamente subductada. Entre hipóteses alternativas para os baixos teores de $\mathrm{Y}$ e $\mathrm{Yb}$, pressupõe-se uma fonte por fusão parcial de rocha contendo piroxênio e granada que ficaram como restitos após a fusão parcial. Tal hipótese explicaria também o padrão inclinado dos elementos terras raras pesados. Teores de $\mathrm{Rb}, \mathrm{Y}+\mathrm{Nb}$ indicam ambiente pós-colisional e os teores de $\mathrm{Ce}, \mathrm{Y}, \mathrm{Nb}$ e Ga indicam uma transição de fonte mantélica para fontes crustais. Uma das hipóteses que tem sido apresentada para gerar fusões de crosta mais antiga sugerem um processo de underplating originado de ascensão de magmas máficos. Os granitos da Suíte Intrusiva Rio Dourado são aqui interpretados como granitos do tipo A oxidados similares aos granitos tipo A da Serra do Carajás e aos Granitos Jamon, diferindo, portanto do Granito Velho Guilherme que é um granito tipo A reduzido (Dall'Agnol et al., 1999a, 1999b; Dall'Agnol e Oliveira, 2007).

A idade U-Pb de 1,88 Ga obtida para os granitos da Suíte Intrusiva Rio Dourado Ga indicam que estão intimamente associados com rochas vulcânicas de caráter félsico a intermediário do Grupo Iriri (1,87 a 1,89 Ga).

As razões isotópicas do granitos aqui estudados mostram $\varepsilon_{\mathrm{Nd}}$ negativos (-3 a -10 Ga) e Tdm entre 2,61 a 2,84 Ga sugerindo uma origem a partir de refusão de crosta arqueana.

Enxame de diques de diabásios, intrusões gabroicas acamadas e corpos gabroicos com textura lamprofírica na região, embora ainda não datados, sugerem que estes foram os responsáveis pelo calor necessário para o processo de fusão parcial de crosta mais antiga.

\section{AGRADECIMENTOS}

Os autores agradecem ao $\mathrm{CNPq}$ processos $\mathrm{N}^{\circ}$ 475722/2009-4, 552880/2009-4 e 556826/2009-4, ao laboratório de geocronologia da UnB, aos revisores anônimos, e as sugestões e críticas do Prof. Jorge Silva Bettencourt.

\section{REFERÊNCIAS}

ALMEIDA, M. E.; MACAMBIRA, M. J. B.; SCHELLER, $\mathrm{T}$. Içana intrusive suíte: age ${ }^{207} \mathrm{~Pb} /{ }^{206} \mathrm{~Pb}$ (zircon evaporation) of muscovite-bearing granite, Amazonas State, Brazil. In: SOUTH-AMERICAN SYMPOSIUM ON ISOTOPE GEOLOGY, 1., 1997, Campos do Jordão. Extended abstracts... Campos do Jordão: SBG/São Paulo, 1997. p. 31-33.

AVELAR, V. G.; LAFON, J. M.; SCHELLER, T.; ARAÚJO, O. J. B.; MACAMBIRA, E. M. B. Geocronologia $\mathrm{Pb}-\mathrm{Pb}$ por evaporação de zircão e $\mathrm{Rb}$ $\mathrm{Sr}$ em rocha total do Granito Seringa, Província Mineral do Carajás. In: CONGRESSO BRASILEIRO DE GEOLOGIA, 38., 1994, Balneário Camboriú. Boletim de resumos expandidos... Balneário Camboriú : SBG. 1994. v. 2, p. 387-389. 
BARBOSA, A. A.; LAFON, J. M.; NEVES, A. P.; VALE, A. G. Geocronologia $\mathrm{Rb}-\mathrm{Sr}$ e $\mathrm{Pb}-\mathrm{Pb}$ do Granito Redenção, SE do Pará: implicações para a evolução do magmatismo proterozóico da região de Redenção. Boletim do Museu Paraense Emílio Goeldi, v. 7, p. 147-164, 1995.

BARROS, M. A. S.; CHEMALE JR., F.; NARDI, L. V. S.; LIMA, E. F. Paleoproterozoic bimodal postcollisional magmatism in the southwestern Amazonian Craton, Mato Grosso, Brazil. Geochemistry and isotopic evidence. Journal of South American Earth Sciences. v. 27 , p. 11-23, 2009.

BARROS, M. A. S.; PADILHA, R. A.; RUBERT, R. R.; PIMENTEL, M. M.; CHEMALE JR, F. Iriri volcanism and Rio Dourado Granite: A-Type Paleoproterozoic Magmatism in northeastern Mato Grosso - Brazil. In: SYMPOSIUM ON MAGMATISM, CRUSTAL EVOLUTION, AND METALLOGENESIS OF THE AMAZONIAN CRATON / WORKSHOP ON A-TYPE GRANITES AND RELATED ROCKS THROUGH TIME (IGCP 510), 2006, Belém. Abstract volume and Field Trips Guide... Belém: PRONEXUFPA/SBG-NO, 2006. p. 39-39.

BARROS, M. A. S.; PIMENTEL, M. M.; DANTAS, E. L.; PADILHA, R. A. Geoquímica e dados isotópicos da suíte intrusiva Vila Rica e suíte intrusiva Rio Dourado - Mato Grosso, área Xingú - Província Amazônia Central - Sul do Craton Amazônico. In: SIMPÓSIO DE VULCANISMO E AMBIENTES ASSOCIADOS, 4., 2008, Foz do Iguaçu. Anais... Cascavel, PR: Coluna do Saber, 2008. (CD-ROM).

BETTENCOURT, J. S.; TOSDAL R. M.; LEITE JR., W. B.; PAYOLLA, B. L. Overview of the rapakivi granites of the Rondônia Tin Province (RTP). In: BETTENCOURT, J. S.; DALL'AGNOL, R. (Ed). Excursion Guide: the rapakivi granites of the Rondônia Tin Province and associated mineralization. IGCP PROJECT 315. Belém, Pará, 1995. p. 48.

BETTENCOURT J. S.; TOSDAL R. M.; LEITE JR., W. B.; PAYOLLA, B. L. Mesoproterozoic rapakivi granites of the Rondônia Tin Province, southwestern border of the Amazonian Craton, Brazil. I Reconnaissance U-Pb geochronology and regional implications. Precambrian Research, v. 95, p. 41-67, 1999.

COSTI, H. T.; DALL'AGNOL, R.; MOURA, C. A. V. Geology and $\mathrm{Pb}-\mathrm{Pb}$ Geochronology of Paleoproterozoic Volcanic and Granitic Rocks of Pitinga Province, Amazonian Craton, Northern Brazil. International Geology Review, v. 42, n. 9, p. 832-849, 2000.
CUNHA, B. C. C.; POTIGUAR, L. A. T.; LANHEZ, A. C.; BEZERRA, P. E. L.; PITTHAN, J. H. L.; SOUZA JUNIOR, J. J.; MONTALVÃO, R. M. G.; SOUZA, A. M. R. H.; HILDRED, P. R.; TASSINARI, C. C. G. Projeto Radambrasil. Brasil-Folha SC.22 - Tocantins. Geologia. Rio de Janeiro: Ministério das Minas e Energia. Departamento Produção Mineral. 1980. p. 21-196.

DALL'AGNOL, R.; COSTI, H. T.; LEITE, A. A. S.; MAGALHAES, M. S.; TEIXEIRA, N. P. Rapakivi granites from Brazil and adjacent areas. Precambrian Research, v. 95, p. 9-39, 1999 b.

DALL'AGNOL, R.; LAFON, J. M.; MACAMBIRA, M. J. M. Proterozoic anorogenic magmatism in the Central Amazonianian Province, Amazonianian Craton: geochronological, petrological and geochemical aspects. Mineral Petrology, v. 50, p. 113-138, 1994.

DALL'AGNOL, R.; OLIVEIRA, D. C. Oxidized, magnetite-series, rapakivi-type granites of Carajás, Brazil: implications for classification and petrogenesis of A-type granites. Lithos, v. 93, p. 215-233, 2007.

DALL'AGNOL, R.; PICHAVANT, M.; CHAMPENOIS, M. Iron-Titanium Oxide Minerals of the Jamon Granite, Eastern Amazonian Region, Brazil: Implications for the Oxygen Fugacity in Proterozoic, A-Type Granites. Anais da Academia Brasileira de Ciências, v. 69, n. 3, p. 325-247, 1997.

DALL'AGNOL, R.; RÄMÖ, O. T.; MAGALHÃES, M. S.; MACAMBIRA, M. J. B. Petrology of the Anorogenic Oxidized Jamon and Musa Granites, Amazonian Craton: Implications for the Genesis of the proterozoic A type Granites. Lithos, v. 46, n. 3, p. 431-462, 1999a.

DALL'AGNOL, R.; SILVA, C. M. G.; SCHELLER, T. Faylite-hedembergite rhyolites of the Formation, Tapajós gold province, Amazonianian Craton: implications for the Uatumã volcanism. In: SIMPÓSIO SOBRE VULCANISMO e AMBIENTES ASSOCIADOS, 1., 1999, Gramado. Boletim de resumos... Gramado, 1999. p. 31.

DALL'AGNOL, R.; TEIXEIRA, N. P.; RÄMÖ, O. T.; MOURA, C. A. V.; MACAMBIRA, M. J. B.; OLIVEIRA, D. C. Petrogenesis of the Paleoproterozoic, rapakivi, A-type granites of the Archean Carajás Metallogenic Province, Brazil. Lithos, v. 80, n. 1-4, p. 101-129, 2005.

DE PAOLO, D. I. Neodymium Isotopes in the Colorado Front Range and Crust- Mantle Evolution in the Proterozoic. Nature, v. 299, p. 193-196, 1981. 
EBY, G. N. Chemical subdivision of the A-Type granitoids: petrogenetic and tectonic implications. Geology, v. 20, p.641-644, 1992.

FERRON, J. M. T. M. Geologia regional, geoquímica e geocronologia $\mathrm{Pb}-\mathrm{Pb}$ de rochas graníticas e vulcânicas paleoproterozóicas da Província Pitinga, Craton Amazônico. 2006. 331 f. Tese (Doutorado)-Instituto de Geociências, Universidade Federal do Rio Grande do Sul, Porto Alegre, 2006.

FROST, B. R.; RONALD BARNES, C. G.; COLLINS, W. J.; ARCULUS, R. J.; ELLIS D. J.; FROST, C. A Geochemical Classification for Granitic Rocks. Journal of Petrology, v. 42, p. 2033-2048, 2001.

GERALDES, M.; TEIXEIRA, W.; SCHMUS, W. R. V. Isotopic and chemical evidence for three accretionary magmatic arcs (1.79-1.42 Ga.) in the SW Amazonian Craton, Mato Grosso State, Brazil. Revista Brasileira de Geociências, v. 30, n. 1, p. 99-101, 2000.

HAAPALA, I.; RÄMÖ, O. T. Tectonic settings and origin of the Proterozoic rapakivi granites of the southeastern Fennoscandia. Transactions of the Royal Society of Edinburgh. Earth Sciences, v. 83, p. 165-171, 1992.

JOÃO, X. S.; SANTOS, C. A.; PROVOST, A. Magmatismo adamelítico Água Branca (Folha Rio Mapuera - NW do Estado do Pará). In: SIMPÓSIO GEOLÓGICO DA AMAZÔNIA, 2., 1985, Belém. Anais... Belém: SBG, 1985. v. 2, p. 93-109.

KROGH, T. E. A low contamination method for hydrotermal decomposition of zircon and extraction of $\mathrm{U}$ and $\mathrm{Pb}$ for isotopic age determinations. Geochimica et Cosmochimica Acta, v. 37, p. 485-494, 1973.

LACERDA FILHO, J. V.; ABREU FILHO, W.; VALENTE, C. R.; OLIVEIRA, C. C.; ALBUQUERQUE, M. C. Geologia e recursos minerais do estado de Mato Grosso. Goiânia: CPRM. 2004. 200 p. Escala 1:1.000.000.

LAMARÃO, C. N.; DALL'AGNOL, R.; LAFON, J. M.; LIMA, E. F. As associações vulcânicas e plutônicas de Vila Riozinho e Morais Almeida, Província Aurífera do Tapajós, SW do estado do Pará. In: SIMPÓSIO SOBRE VULCANISMO E AMBIENTES ASSOCIADOS, 1., 1999, Gramado. Boletim de resumos... Gramado, 1999. p. 93.

LAMARÃO, C. N.; DALL'AGNOL, R.; LAFON, J. M.; LIMA, E. F. Geology, geochemistry, and $\mathrm{Pb}-\mathrm{Pb}$ zircon geochronology of the Paleoproterozoic magmatism of Vila Riozinho, Tapajós Gold Province, Amazonian Craton, Brazil. Precambrian Research, v. 119, n. 1, p. 189-223, 2002.

LOISELLE, M. C.; WONES, D. R. Characteristics and origin of anorogenic granites. Geological Society of America. Abstracts with programs, v. 11, p. 468, 1979.

MACAMBIRA, M. J. B. Chronologie U-Pb, $R b-S r, K-A r$ et croissance de la croûte continentale dans l'Amazonie du sul-est; example de la région de Rio Maria, Province de Carajás. 1992. Tese (Doutorado)-Universidade de Montpellier II, Montpellier, 1992.

MACAMBIRA, M. J. B.; LAFON, J. M. Geocronologia da Província Mineral de Carajás: síntese dos dados e novos desafios. Boletim do Museu Paraense Emílio Goeldi, v. 7, p. 263-288, 1995.

MACHADO, N.; LINDERNMAYER, Z.; KROGH, T. E. U/Pb geochronology of acrhean magmatismo and basement reactivation in the Carajás area, Amazon shield, Brazil. Precambrian Research, n. 49, p. 329-354, 1991.

MANIAR, P. D.; PICCOLI, P. M. Tectonic discrimination of granitoids. Geological Society of America Bulletin, v. 101, 635-643, 1989.

MOURA, C. A V.; GORAYEB, P. S.; MATSUDA, N. $\mathrm{S}$. Geocronologia $\mathrm{Pb}-\mathrm{Pb}$ em zircão do riolito Vila Raiol, Formação Iriri, sudoeste do Pará. In: SIMPÓSIO DE GEOLOGIA DA AMAZÔNIA, 6., 1999, Manaus. Boletim de resumos expandidos... Manaus: SBG, 1999. p. 475-477.

OLIVEIRA, D. C. Geologia, geoquímica e petrologia magnética do granito paleoproterozóico Redenção, SE do Craton Amazônico. 2001. 207 f. Dissertação (Mestrado) Universidade Federal do Pará, 2001.

PADILHA, R. A. Petrologia e Geoquímica dos granitos da Suite Intrusiva Vila Rica e do Granito Rio DouradoBorda Sudeste do Craton Amazônico (Província Amazônia Central - Área Xingu-Iricoumé-Nordeste de Mato Grosso). 2007. Trabalho de Conclusão de Curso-Instituto de Ciências Exatas de da Terra, Universidade Federal de Mato Grosso, Cuiabá, 2007.

PADILHA, R. A.; BARROS, M. A. S. Petrologia e Geoquimica da Suítes Intrusiva Vila Rica e Rio Dourado - Província Amazônia Central. Revista Brasileira de Geociências, v. 38, p. 38-42, 2008. 
PARRISH, R. R. Na Improved micro-capsule for zircon dissolution in $\mathrm{U}-\mathrm{Pb}$ geochronology. Isotopic Geoscience, v. 66, p. $99-102,1987$.

PATCHETT, P. J.; RUIZ, J. Nd isotopic ages of crust formation and metamorphism in the Precambrian of eastern and southern Mexico. Contributions to Mineralogy and Petrology, v. 96. p. 523-528, 1987.

PATIÑO DOUCE, A. E. Generation of metaluminous A-Type granites by low-pressure melting of calc-alkaline granitoids. Geology, v. 25. p. 743-746, 1997.

PEARCE, J. A. Sources and Settings of granitic rocks. Episodes, v. 19, p. 120-125, 1996.

PIEROSAN, R. Geologia, Litoquímica e Química mineral do Grupo Iricoumé e da Formação Qarenta Ihas no Distrito Mineiro de Pitinga - AM, Brasil. 2009. 423 f. Tese (Doutorado) - Instituto de Geociências da UFRGS, Porto Alegre, RS, 2009.

PINHO, F. E. C.; PINHO, M. A. S. B.; PIMENTEL, M.; SOUZA, D. G.; RIBEIRO, J. N.; SILVA, M. A. P. e BERLANDI, R. A.; SANTOS, A. A.; CABRAL, C. Reconhecimento geológico e geocronológico do Craton Amazônico na região nordeste de Mato Grosso. In: SIMPÓSIO DE GEOLOGIA DO CENTRO-OESTE, 8., 2003, Cuiabá. Anais... Cuiabá: SBG, 2003. p. 90-92.

PINHO, M. A. S. B.; RUBERT, R. R.; SILVA, G. D.; CHEMALE JR., F.; DUSSIN, I. A.; COSTA, E. C. Dados petrográficos, geoquímicos e idades U-Pb da vulcânica félsica do Grupo Iriri na porção nordeste de Mato Grosso - Serra dos Magalhães. In: CONGRESSO BRASILEIRO DE GEOLOGIA, 42., 2004, Araxá. Recursos minerais e desenvolvimento socioeconômico... s.l.: SBG, 2004. (CD-ROM).

SANTOS, J.O.S.;HARTMANN,L.A.; McNAUGHTON, N. J.; FLETCHER, I. R. Timming of mafic magmatism in the Tapajós Province (Brazil) and implications for the evolution of the Amazon Craton: evidence from baddeleyite and zircon U-Pb SHRIMP geochronology. Journal of South America Earth Sciences, v. 15, n. 4, p. 409-429, 2002.

SANTOS, J. O. S.; REIS NETO, J. M. Algumas idades de rochas graníticas do Craton Amazônico. In: CONGRESSO BRASILEIRO DE GEOLOGIA, 32., 1982, Salvador. Anais... Salvador: SBG, 1982. v. 5, p. 339-348.
SAUNDERS, A. D.; TARNEY, J.; WEAVER, S. D. Transverse geochemical variations across the Antartic peninsula; implication for the genesis of calc-alkalic magmas. Science Letters, v. 46. p. 344-360, 1980.

STRECKEISEN, A. L. To each plutonic rock its proper name. Earth Science Reviews, v. 12. p. 1-13, 1976.

TASSINARI, C. C. G.; BETTENCOURT, J. S.; GERALDES, M. C.; MACAMBIRA, M. J. B.; LAFON, J. M. The Amazonian Craton. In: CORDANI, U.; MILANI, E. J.; THOMAZ FILHO, A.; CAMPOS, D. A. (Ed.). TECTONIC EVOLUTION OF SOUTH AMERICA / INTERNATIONAL GEOLOGICAL CONGRESS, 31., Rio de Janeiro, 2000. p. 41-95.

TASSINARI, C. C. G.; CORDANI, U.G.; NUTMAN, A.P.; SCHMUS, W. R. V.; BETTENCOURT, J. S.; TAYLOR, P. N. Geochronological systematics on basement rocks from the Rio Negro-Juruena Province (Amazonian Craton) and tectonic implications. International Geology Review, v. 38, n. 2, p. 1161-175, 1996.

TASSINARI, C. C. G.; MACAMBIRA, M. J. B. Geochronological provinces of the Amazonian Craton. Episode, v. 22, n. 3, p. 174-182, 1999.

TEIXEIRA, N. P.; BETTENCOURT, J. S.; MOURA, C. A. V.; DALL'AGNOL, R.; MACAMBIRA, E. M. B. Archean crustal sources of Paleoproterozoic tin. mineralized granites in the Carajás province, SSE Pará, Brazil: $\mathrm{Pb}-\mathrm{Pb}$ geochronology and $\mathrm{Nd}$ isotope geochemistry. Precambrian Research, v. 119, n. 1-4, p. 257-275, 2002.

TOSDAL, R. M.; BETTENCOURT, J. S.; LEITE JR., W. B.; PAYOLLA, B. L. U-Pb geochronologic framework of Mesoproterozoic rapakivi granites of the Rondonia Tin Province. In: CONGRESSO BRASILEIRO DE GEOLOGIA, 1996. v. 7, p. 337-339.

VALÉRIO; C. S.; SOUZA, V. S.; MACAMBIRA, M. J. B.; GALARZA, M. A. Aspectos geoquímicos e idade Pb$\mathrm{Pb}$ da borda sudeste do Batólito São Gabriel, Município de Presidente Figueiredo (AM), Escudo das Guianas: implicações tectônicas. In: SIMPÓSIO DE GEOLOGIA DA AMAZÔNIA, 9., 2006, Belém. Resumos Expandidos... Belém, 2006. (CD-ROM).

VASQUEZ, M. L.; KLEIN E. L. Projeto Especial Província Mineral do Tapajós. Geologia e recursos minerais da folha Rio Novo (SB.21-Z-C), 2000. Estado do Pará. Belém: CPRM, 2000. 
VASQUEZ, M. L.; KLEIN, E. L.; QUADROS, M. L. E.; BAHIA, R. B. C.; SANTOS, A.; RICCI, P. S. F.; SACHETT, R.; SILVA, C. M. C.; MACAMBIRA, M. J. B. Magmatismo Uatumã na Província Tapajós. Novos dados geocronológicos. In: SIMPÓSIO DE GEOLOGIA DA AMAZÔNIA, 6, 1999. Manaus. Boletim de Resumos... Manaus: SBG. 1999. p. 471-474.

VASQUEZ, M. L.; MACAMBIRA, M.; ARMSTRONG, R. Zircon geochronology of granitoids from the western Bacajá domain, southeastern Amazonian Craton, Brazil: Neoarchean to Orosirian evolution. Precambrian Research, v. 161, p. 279-302, 2008.

VASQUEZ, M. L.; ROSA-COSTA, L. T. Geologia e Recursos Minerais do Estado do Pará: texto explicativo do mapa geológico e de recursos minerais do estado do Pará: escala 1:1.000.000. Belém: CPRM, 2008. 328 p. (CD-ROM).

WHALEN, J. B.; CURIE, K. L.; CHAPPELL, B. W. A-type granites: geochemical characteristics, discrimination and petrogenesis. Contributions to Mineralogy and Petrology, v. 95 , n. 4, p. 407-419, 1987. 
